\title{
Finite element modelling and design of steel plate shear wall buckling-restrained by hat-section cold-formed steel members
}

DOI:

10.1016/j.jcsr.2020.106274

\section{Document Version \\ Accepted author manuscript}

Link to publication record in Manchester Research Explorer

Citation for published version (APA):

Tan, J., Gu, C., Su, M., Wang, Y., Wang, K., Shi, Y., Lan, Y., Luo, W., Deng, X., Bai, Y., \& Chen, Q. (2020). Finite element modelling and design of steel plate shear wall buckling-restrained by hat-section cold-formed steel members. Journal of Constructional Steel Research, 174, 106274. [106274].

https://doi.org/10.1016/j.jcsr.2020.106274

\section{Published in:}

Journal of Constructional Steel Research

\section{Citing this paper}

Please note that where the full-text provided on Manchester Research Explorer is the Author Accepted Manuscript or Proof version this may differ from the final Published version. If citing, it is advised that you check and use the publisher's definitive version.

\section{General rights}

Copyright and moral rights for the publications made accessible in the Research Explorer are retained by the authors and/or other copyright owners and it is a condition of accessing publications that users recognise and abide by the legal requirements associated with these rights.

\section{Takedown policy}

If you believe that this document breaches copyright please refer to the University of Manchester's Takedown Procedures [http://man.ac.uk/04Y6Bo] or contact uml.scholarlycommunications@manchester.ac.uk providing relevant details, so we can investigate your claim.

\section{OPEN ACCESS}


Tan J.K., Gu, C.W., Su, M.N., Wang, Y.H., Wang, K., Shi, Y., Lan, Y.S., Luo, W., Deng X.W., Bai, Y.T., Chen Q., (2020), "Finite element modelling and design of steel plate shear wall buckling-restrained by hat-section cold-formed steel members", Journal of Constructional Steel Research, 174: 106274.

\section{Finite element modelling and design of steel plate shear wall}

\section{buckling-restrained by hat-section cold-formed steel members}

Ji-Ke Tan a, Chao-Wei Gu ${ }^{\text {b }}$, Mei-Ni Su ${ }^{\text {c, d, }}$, Yu-Hang Wang a*, d, Kang Wang a , Yu Shi ${ }^{\text {a }}$, Yong-Sen

Lan ${ }^{\mathrm{e}}$, Wei Luo ${ }^{\mathrm{e}}$, Xiao-Wei Deng ${ }^{\mathrm{f}}$, Yong-Tao Bai ${ }^{\mathrm{a}}$, Qing Chen ${ }^{\mathrm{e}}$

${ }^{a}$ School of Civil Engineering, Chongqing University, Chongqing 400045, China

${ }^{\mathrm{b}}$ China Overseas Property Co., Ltd.(Jinan), Jinan 250000, China

${ }^{c}$ Key Laboratory of New Technology for Construction of Cities in Mountain Area (Chongqing University), Ministry of Education, Chongqing 400045, China

Abstract: Steel plate shear wall (SPSW) buckling-restrained by hat-section cold-formed steel is a new type of lateral bearing system that uses hat-section cold-formed steel members to restrain the buckling deformation of the SPSW. Integration of architectural and structural functions is achieved in this new shear wall system by externally bonding oriented strand board (OSB) and filling sound insulation material. A finite element (FE) model was developed and validated against seven experimental results in terms of failure modes, shear force-story drift angle curves and shear bearing capacities. Upon validation, an extensive parametric study was carried out to investigate the six key parameters including spacing of connecting bolts, geometries of hat-section steel, spacing of hat-section steel, steel material strength, width-height ratio of the SPSW and height-thickness ratio of the SPSW. Based on the 104 numerical results, new design rules are proposed to predict the stiffness, shear yielding strength and shear ultimate strength of this new type of buckling-restrained SPSW structure. By comparing the predicted results with experimental and numerical results, the proposed design method is found to be accurate and consistent. In addition, an equivalent cross-bar model is developed as a simplified substituted SPSW model to be used in theoretical modelling programmes in the future.

Keywords: Buckling-restrained; Cold-formed steel; Design rules; Numerical modelling; Steel plate shear wall

* Corresponding author: wangyuhang@cqu.edu.cn (Y.H. WANG). 
35 Steel plate shear wall (SPSW) is a new type of highly efficient lateral force resisting system 36 developed in the 1970s. Compared with the traditional reinforced concrete shear wall, the SPSW enjoys the advantages of good ductility, superior seismic performance, light weight and high construction efficiency, easy repairing, easy dismantling and recyclability [1-4]. In recent years, a number of research have been carried out on the theory and test of the thin SPSW (height-to-thickness ratio of steel plate $(\lambda)>150$ ). The research results show that there are some deficiencies in the mechanical performance of thin SPSW, such as: the hysteresis loop "pinching" phenomenon is caused by the out-of-plane buckling deformation of steel plate wall under cyclic horizontal loading [5]; the noise and vibration of the deformation process affect the applicability performance of the structure [6]; and the appearance of the tension field would bring additional bending moment to the vertical edge component [7]. In order to change the insufficient seismic behaviour caused by the excessive out-of-plane deformation of the steel plate, it is necessary to find a reasonable technical measure to prevent the out-of-plane buckling of SPSW, for example the welding stiffener constraint [8], the precast concrete cover constraint [5], the multi-ribbed grid constraint [9], etc. The SPSW is mainly in the state of plane shear stress before shear buckling. With the increase of the lateral shear deformation, the steel plate appears the external oblique buckling deformation, and the lateral resistance of the structure is changed from the plane shear resistance to the lateral resistance mode mainly borne by the oblique tension field. If the measures are taken to reduce the surface deformation of the steel plate, the steel plate will have better shear resistance. The reduction of out-of-plane deformation of the steel plate and the weakening of the tension field have positive effects on the lateral stiffness, bearing capacity and energy dissipation capacity of the structure. Therefore, it is of great significance to carry out the research on the buckling-restrained SPWS structure.

In this study, from the perspective of buckling-restrained SPSW and integration of architectural functional requirements of heat preservation, sound insulation, seepage and decoration of wall, a new type of SPSW buckling-restrained by hat-section cold-formed steel is proposed, as shown in Fig. 1. The hat-section cold-formed steel members (Fig. 2) are installed vertically with bolt through connection on both sides of the embedded SPSW. In order to prevent the hat-section steel members participating in the force deformation with the SPSW and utilize their bending resistance effectively, the size of bolt holes in the SPSW is slightly larger than the diameter of connecting bolts. The hat-section cold-formed steel members have the advantages of light weight, easy manufacture, convenient assembling and construction. Although there are many researches on the design method of SPSW [10][13], the object of these researches is the pure SPSW, which may not be applicable to 
the SPSW buckling-restrained by hat-section cold-formed steel proposed in this paper. Therefore, it is necessary to propose a design method for this new type of SPSW. Wang et al. [14] has carried out experimental research on seven specimens of SPSW buckling-restrained by hat-section cold-formed steel, however, the research only focuses on the preliminary qualitative exploration of the seismic performance of this new type of SPSW, which cannot be used as a reference for design. Therefore, in order to facilitate the practical application of this new type of SPSW and considering that the number of specimens considered for the test is too small, the parametric analysis is carried out based on the finite element (FE) model, and the design method of the SPSW buckling-restrained by hat-section cold-formed steel is proposed based on the FE analysis results.

In this paper, a FE model of this new type of buckling-restrained SPSW is presented. The model was validated against seven experimental results reported by Wang et al. [14]. Upon validation, a total of $104 \mathrm{FE}$ results were generated in the parametric analysis. Based on the theoretical analysis and numerical results, a cross-bar model for calculating the stiffness and strength of the buckling-restrained SPSW is developed. Afterwards, a new design method is proposed to predict the stiffness, shear yielding strength and shear ultimate strength of buckling-restrained SPSW by hat-section cold-formed steel.

\section{Summary of tests}

A total of seven SPSW buckling-restrained by hat-section cold-formed steel members have been tested under low-cycle reversed shear load [14]. As illustrated in Fig. 1, the specimens were comprised of one embedded SPSW and hat-section cold-formed steel members on both sides, connected by M12 high-strength steel bolts. The dimensions of the embedded steel plates were all $1080 \times 1080 \times 2.66 \mathrm{~mm}$ (height $\times$ width $\times$ thickness); the plates were connected to four sides of the loading device (see Fig. 3) by twelve M24 high-strength steel bolts of grade 10.9. The dimensions of oriented strand board (OSB) were $1000 \times 1000 \times 15 \mathrm{~mm}$ (height $\times$ width $\times$ thickness). Note that the specimen NRSP was a pure SPSW as a reference comparison specimen. The detailed parameters of all specimens are reported in Ref. [14] and the corresponding material properties are shown in Table 1. The test was carried out by load-displacement hybrid control $[14,15]$.

\section{Finite element modelling}

The non-linear finite element (FE) analysis package ABAQUS 6.14 [16] was employed in the numerical investigation herein. For the FE model, geometric nonlinearity and material nonlinearity are considered, and Newton-Raphson method is used to solve the balance equation in ABAQUS/Standard analysis module. An automatic stabilization method is adopted to improve the convergence of the calculation. The loading of the experimental programme was reasonably 
101

102

103

104

105

106

107

108

109

110

111

112

simplified in the modelling process to balance the efficiency and accuracy of the program calculation. A new FE model of the SPSW buckling-restrained by hat-section cold-formed steel members was developed, as illustrated in Fig. 4.

\subsection{Material models}

An ideal elastic-plastic constitutive model was adopted for the hat-section cold-formed steel members with the yield stress $\sigma_{\mathrm{y}}=345 \mathrm{MPa}$. A two-stage cyclic skeleton constitutive was adopted for the embedded SPSW [17] based on the results of tensile coupon, as given by Eq. (1):

$$
\tilde{\sigma}= \begin{cases}\tilde{\varepsilon} & , \quad \tilde{\varepsilon} \leq 1 \\ \frac{\tilde{\varepsilon}+5.796}{2.486+0.608 \cdot(\tilde{\varepsilon}+5.796)-0.00046 \cdot(\tilde{\varepsilon}+5.796)^{2}}, & \tilde{\varepsilon}>1\end{cases}
$$

where, $\tilde{\varepsilon}\left(\varepsilon=\varepsilon / \varepsilon_{\mathrm{y}}\right)$ and $\tilde{\sigma}\left(\tilde{\sigma}=\sigma / \sigma_{\mathrm{y}}\right)$ are the regularized strain and stress respectively; $\varepsilon_{\mathrm{y}}$ is the yield strain, $\sigma_{\mathrm{y}}$ is the yield stress.

The stress and strain curves of steel materials were determined from tensile coupon tests. For FE model, the true stress $\sigma_{\text {true }}$ and the plastic strain $\varepsilon_{\mathrm{pl}}$ are calculated based on nominal (engineering) strain $\varepsilon_{\text {nom }}$ and nominal (engineering) stress $\sigma_{\text {nom, }}$ as shown in Eqs. (2) and (3), where $E$ is the Young's modulus.

$$
\begin{gathered}
\sigma_{\text {true }}=\sigma_{\text {nom }}\left(1+\varepsilon_{\text {nom }}\right) \\
\varepsilon_{\mathrm{pl}}=\ln \left(1+\varepsilon_{\text {nom }}\right)-\frac{\sigma_{\text {true }}}{E}
\end{gathered}
$$

\subsection{Finite element type and mesh}

The two columns of the loading device were considered as rigid body, so beam element (B31) was employed for the simulation. Shell element (S4R) was used for both embedded SPSW and hat-section cold-formed steel members as widely employed for metallic structures [18, 19]. After the mesh sensitivity analysis with consideration of the balance of mesh density and time cost, the final mesh size was selected as $10 \times 10 \mathrm{~mm}$.

\subsection{Loading and boundary conditions}

A uniaxial simplified constitutive model of steel under cyclic load was adopted and the hysteretic cyclic loading can be simulated by monotone loading [17]. A reference point RP1 (see Fig. 4) was established, and the translational degrees of freedom of U1, U2 and U3 at the top of the column on both sides of the loading device and the shear wall on the steel plate were coupled to reference point RP1. Horizontal lateral displacement (U1) was applied to the reference point RP1 and the vertical 
translational degree of freedom U2 was released. Meanwhile, the translational degree of freedom U3 and three rotational degrees of freedom UR1, UR2 and UR3 were fixed (see Fig. 4).

At the bottom of columns, the one-way hinge constraint which only releases the rotational degree of freedom in the vertical plane (UR3) was adopted to achieve the four-side hinged connection of the loading device. The columns were connected to both sides of the embedded SPSW by "Tie" constraints. The bottom edge of the steel plate was constrained by fixing the translational degrees of freedom. The translational freedom U3 within the range of $60 \mathrm{~mm}$ on the four edges of the embedded steel plate (i.e. the outer edge range of the nut of the high-strength bolt in the test) was restricted to consider the constrain effect of fishtail plate on the embedded steel plate in the loading process.

\subsection{Contact interaction and interfaces}

The "surface-to-surface" contact was used to simulate the interaction between the hat-section cold-formed steel members and the SPSW. The master surface was defined as the SPSW surface and the slave surface was chosen as the surface of hat-section cold-formed steel member [20]. In the tangential direction, the contract surface was considered as frictionless.

The sliding connection bolts were simulated by "Connector" in ABAQUS. The connectors were adopted at the bolt geometric centre of hat-section cold-formed steel member and the SPSW. The hat-section steel members and SPSW were not allowed to separate in the normal direction; in the tangential direction the relative sliding range was allowed to simulate the partially sliding connection bolts.

\subsection{Initial geometric imperfection}

The thickness of the steel plate in the SPWS structure was small, and corresponding out-of-plane stiffness was also small. Therefore, in the process of manufacture, transportation and installation, initial geometric imperfections on steel plates and hat-section steel members are unavoidable. This study considers the initial geometric imperfection of the specimens by conducting eigenvalue buckling analysis subjected to the monotonic loading. The first buckling mode obtained from FE modelling of each specimen is shown in Fig. 5. The magnitude of the imperfection was taken as $1 / 1000$ of the height of the SPSW.

\subsection{Validation of FE model}

Fig. 6 shows the failure modes of SPSW obtained by test and FE model. The cross fold and tear of SPSW observed in the test also occurred at the corresponding place of the FE results. Fig. 7 shows the comparison between the shear force-story drift angle curves obtained by the FE simulation 
158 monotone loading and the hysteresis loading test. It can be seen that experimental and FE curves of

159 all specimens agree well. Table 2 summarises the shear yielding strength and shear ultimate strength

160 by test [14] and FE modelling. According to Ref. [15], the drift ratio at yielding is determined by the

161 yield inflection point of skeleton curve and the ultimate drift angle is the displacement angle

162 corresponding to $85 \%$ of the ultimate load. To conclude, good agreements between the experimental

163 and FE results have been achieved in terms of failure modes, shear-story drift angle curves and shear 164 strength. The accuracy of the new FE model simulating the loading performance of 165 buckling-restrained SPSW is demonstrated.

166 For the test results, according to Ref. [15], the stiffness of the specimen is the initial stiffness 167 before the yield of the specimen. According to the skeleton curve of the specimen obtained from the 168 test results, the yield bearing capacity of the specimen is the load corresponding to obvious yield on 169 the skeleton curve. The ultimate bearing capacity of the specimen is the peak load on the skeleton 170 curve. For the FE results, the stiffness of the specimen is the elastic stiffness of the 171 load-displacement curve obtained by FE analysis. The yield bearing capacity is the load 172 corresponding to the obvious yield in the load-displacement curve of the specimen. Because it is 173 difficult to simulate the damage and fracture of steel plate, the load-displacement curve of the 174 specimen obtained by FE analysis does not show a descending stage. Therefore, according to Ref. 175 [21], defined as the load at the displacement angle of $\theta_{\mathrm{u}}=0.02$. According to the load-displacement 176 curve of the experimental results, the bearing capacity of the specimen the displacement angle of $177 \theta \mathrm{u}=0.02$ is less than its ultimate bearing capacity. Therefore, the method to determine the ultimate 178 bearing capacity of the specimen calculated by FE method is conservative and feasible.

\section{Parametric study}

\subsection{General}

181 The FE model validated against test results was employed in the parametric study to extensively 182 investigate key parameters including spacing of connection bolts, section geometries and spacing of 183 the hat-section cold-formed steel members, strengths of steel materials, width-height ratio and 184 height-thickness ratio of the embedded SPSW. In order to better reflect the structural characteristics 185 of the structure, a simplified two-stage skeleton of $F-\theta$ curve model is proposed (see Fig. 8). Effects 186 of the aforementioned parameters on the lateral stiffness $\left(K_{\mathrm{e}}\right)$, shear yielding strength $\left(F_{\mathrm{ym}}\right)$ and shear 187 ultimate strength ( $F_{\mathrm{um}}$, defined as the load at the displacement angle of $\theta_{\mathrm{u}}=0.02$ [21],) of the SPSW 188 buckling-restrained by hat-section cold-formed steel members are discussed in this section. 


\subsection{Spacing of connection bolts}

In parametric study, the benchmark construction FE model of SPSW with dimensions of $1080 \times$ $1080 \times 2.66 \mathrm{~mm}$ (Height $H \times$ width $L \times$ thickness $t$ ) was employed, and the spacing of connection bolts $s_{\mathrm{m}}$ is considered from 120 to $840 \mathrm{~mm}$. As shown in Fig. 9, with the increase of the spacing of connection bolts $s_{\mathrm{m}}$ : the stiffness $K_{\mathrm{e}}$ and the shear yielding strength $F_{\mathrm{ym}}$ are basically unchanged; whereas, the shear ultimate strength $F_{\text {um }}$ is rather stable when the spacing of connection bolts $s_{\mathrm{m}}$ is smaller than $168 \mathrm{~mm}$ (i.e. $s_{\mathrm{m}} / t_{\mathrm{m}}=112$, where, $t_{\mathrm{m}}$ is the thickness of hat-section cold-formed steel member), and the shear ultimate strength $F_{\text {um }}$ is gradually decreased when the spacing of connection bolts $s_{\mathrm{m}}$ is greater than $168 \mathrm{~mm}$. The spacing of connection bolts affected the restraint effect of the hat-section steel members to the embedded SPSW. According to the analysis results, it seems that when the $s_{m} / t_{m}$ became larger than $112, F_{u m}$ would decrease gradually. Therefore, it is recommended to limit the spacing of connection bolts $s_{\mathrm{m}}$ in the structure of SPSW buckling-restrained by hat-section cold-formed steel members as shown in Eq. (4):

$$
s_{m} / t_{m} \leq 112
$$

\subsection{Geometries of the hat section}

In parametric study, the benchmark construction FE model of SPSW with dimensions of $1080 \times$ $1080 \times 2.66 \mathrm{~mm}$ (Height $H \times$ width $L \times$ thickness $t$ ) was employed.

\subsubsection{Length of the crimping}

In parametric study, the length of the crimping $l_{\mathrm{m}}$ of the hat-section (as shown in Fig. 2) is considered from 0 to $40 \mathrm{~mm}$. Results summarized in Fig. 10 shows that the length of the crimping $l_{\mathrm{m}}$ has limited effect on the stiffness $K_{\mathrm{e}}$ and shear yielding strength $F_{\mathrm{ym}}$ of the shear wall structure. The shear ultimate strength of $F_{\mathrm{um}}$ of structure improves slightly with increasing of $l_{\mathrm{m}}$, and $F_{\mathrm{um}}$ remains basically unchanged when $l_{\mathrm{m}}$ is larger than $20 \mathrm{~mm}$. According to the height-thickness ratio limit of T-section flexural members [22], the length of the crimping of hat-section cold-formed steel member is suggested to be limited by Eq. (5). If the $l_{\mathrm{m}}$ is larger than this limit, the crimping might buckle locally first, which would greatly reduce the out-of-plane restraint effect on the steel plate.

$$
l_{m} / t_{m} \leq 15 \sqrt{235 / f_{y}}
$$

\subsubsection{Section geometries}

6 The geometries of the hat-sections are expected to have significantly influences on the 
$\mathrm{mm}$ ) are considered in the parametric study. As shown in Fig. 11(a), when the section height $h_{\mathrm{m}}=90$ $\mathrm{mm}$, as the thickness $t_{\mathrm{m}}$ of the hat-section increases: the stiffness $K_{\mathrm{e}}$ and the shear yielding strength $F_{\text {ym }}$ are basically unchanged; the shear ultimate strength $F_{\text {um }}$ increase slightly when the thickness $t_{\mathrm{m}}$ is smaller than $2.5 \mathrm{~mm}$ and keeps the same when the thickness $t_{\mathrm{m}}$ is greater than $2.5 \mathrm{~mm}$,. As can be seen from Fig. 11(b), when the thickness is kept constant as $t_{\mathrm{m}}=1.5 \mathrm{~mm}$, the section height $h_{\mathrm{m}}$ has no effect on the curve stiffness $K_{\mathrm{e}}$ and shear yielding strength $F_{\mathrm{ym}}$, but positive effects on the shear ultimate strength $F_{\text {um }}$. Fig. 11(c) presents the shear ultimate strength $F_{\text {um }}$ with varying section height $h_{\mathrm{m}}$ and cold-formed steel thickness $t_{\mathrm{m}}$.

A bending stiffness ratio $\eta$, defined as the ratio of the out-of-plane bending flexural rigidity of the hat-section members and that of the embedded SPSW on the unit width (given by Eq. (6)), is introduced herein to quantify the restraining effect of the hat-section cold-formed steel member.

$$
\begin{gathered}
\eta=\frac{E_{\mathrm{m}} I_{\mathrm{m}}}{D l} \\
D=\frac{E t^{3}}{12\left(1-v^{2}\right)}
\end{gathered}
$$

where, $D$ is the out-of-plane bending flexural rigidity per unit width of embedded SPSW (given by Eq. (7), where $E, t$ and $v$ are the elastic modulus, thickness and Poisson's ratio of embedded steel plates, respectively); $E_{\mathrm{m}}$ is the elastic modulus of the hat-section cold-formed steel member; $l$ is the width of embedded steel plate restrained by a pair of hat-section members; $I_{\mathrm{m}}$ is the sum of the moment of inertia of the hat-section members.

The relationship between the shear ultimate strength $F_{\text {um }}$ and the bending stiffness ratio $\eta$ is shown in Fig. 11(d). When the thickness of the cold-formed steel is small, as the bending stiffness ratio $\eta$ of the section increases, the shear ultimate strength $F_{\text {um }}$ of the structure improved slightly. For the same bending stiffness ratio $\eta$, the larger of the cold-formed steel thickness $t_{\mathrm{m}}$ lead to a higher

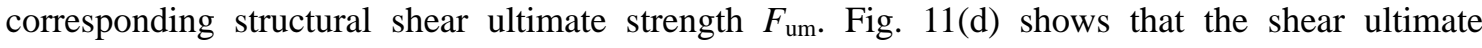
strength $F_{\text {um }}$ reaches its upper bound when the bending stiffness ratio $\eta$ is larger than 211.4 (corresponding to specimen 90-2.5). Based on the above analysis results, it is recommended to limit the bending stiffness ratio as follows:

$$
\eta=\frac{E_{\mathrm{m}} I_{\mathrm{m}}}{D l} \geq 210
$$

Besides, in order to prevent local buckling of the hat-section members, some limits on the cross-sectional dimensions are suggested as follows, with reference to the width-thickness limit reported by Cui and Long [22]:

$$
b_{1 m} / t_{m} \leq 40 \sqrt{235 / f_{y}}
$$




$$
\begin{aligned}
& b_{2 m} / t_{m} \leq 30 \sqrt{235 / f_{y}} \\
& h_{m} / t_{m} \leq 60 \sqrt{235 / f_{y}}
\end{aligned}
$$

where, $b_{1 \mathrm{~m}}, b_{2 \mathrm{~m}}$ and $h_{\mathrm{m}}$ are the flange width, the lower flange width and the web height of the hat section, respectively, as shown in Fig. 2.

\subsection{Spacing of constraints}

A FE model of SPSW with dimensions of $3000 \times 3000 \times 6 \mathrm{~mm}$ (Height $H \times$ width $L \times$ thickness $t$ ) was employed to investigate the effects of the spacing of hat-section members $(S)$, ranging from 375 , 430, 500, 600, 750, and $1000 \mathrm{~mm}$. As illustrated in Fig. 12, some conclusions can be drawn: (1) before the structure yields, the decreasing spacing leads to slight increase of the shear yielding strength $F_{\mathrm{ym}}$, but no change on the stiffness $K_{\mathrm{e}}$; (2) after yielding, the structure enters an elastic-plastic stage, and an out-of-plane buckling tension field occurs in the steel plate between two hat-section cold-formed steel members; (3) the spacing $S$ has negligible effect on the shear ultimate strength $F_{\text {um }}$ when the spacing $S$ was less than $450 \mathrm{~mm}$ (accordingly, $S / t=72$ ). According to the analysis results, considering the influence of steel strength, it is recommended that the spacing of constraints is limited by Eq. (12):

$$
S / t \leq 72 \sqrt{235 / f_{y}}
$$

\subsection{Yield strength of steel material}

The yield strengths of the cold-formed steel materials of the hat-section members $\left(f_{\mathrm{ym}}\right)$ were considered as 235, 345, 390 and $420 \mathrm{MPa}$, and the benchmark construction FE model of SPSW with dimensions of $3000 \times 3000 \times 6 \mathrm{~mm}$ (Height $H \times$ width $L \times$ thickness $t$ ) was employed. The FE results are shown in Fig. 13. It is found to have limited influence on the lateral performance of the structure.

Similarly, the yield strengths of the steel material of embedded SPSW $\left(f_{\mathrm{y}}\right)$ were considered as 235, 345, 390 and $420 \mathrm{MPa}$. It can be seen, as shown in Fig. 14, that the yield strength $f_{\mathrm{y}}$ of the embedded steel wall steel has no effect on the structural stiffness $K_{\mathrm{e}}$. With the increase of the yield strength of steel material, the shear yielding strength $F_{\mathrm{ym}}$ increases consistently. That was probably because when spacing $S$ is within the reasonable range (see Eq. (12)), the in-plane buckling deformation did not occur before the yielding of the embedded steel wall.

\subsection{Geometries of the SPSW}

A FE model of SPSW with dimensions of $3000 \times 3000 \times 6 \mathrm{~mm}$ (Height $H \times$ width $L \times$ thickness $t$ ) 


\section{4.6.1 Width-height ratio}

274 The width $L$ of the embedded SPSW varied from $2250 \mathrm{~mm}$ to $5250 \mathrm{~mm}$ with an interval of $750 \mathrm{~mm}$, 275 and the corresponding width-height ratios $\alpha$ (equal to $L / H$ ) are $0.75,1,1.25,1.5$ and 1.75 . As can be 276 seen from Fig. 15(a)-(c), the structural stiffness $K_{\mathrm{e}}$, the shear yielding strength $F_{\mathrm{ym}}$ and shear 277 ultimate strength $F_{\text {um }}$ all increase linearly with of the width-height ratio. In order to evaluate the 278 utilization efficiency of steel materials of SPSW, an average shear stress of the cross section of the $279 \operatorname{SPSW}\left(\bar{\tau}_{\text {um }}\right)$ is defined as:

$$
\bar{\tau}_{\mathrm{um}}=\frac{F_{\mathrm{um}}}{t L}
$$

Fig. 15(d) shows the relationship between the width-height ratio $\alpha$ and the average shear stress $\bar{\tau}_{\text {um }}$, which generally follows a parabolic trend.

\subsubsection{Height-thickness ratio}

In order to investigate effects of the height-thickness ratio of SPSW ( $\lambda$, defined as $H / t$ ), the thickness of the embedded SPSW

( $t$ ) are varied from $5 \mathrm{~mm}$ to $12 \mathrm{~mm}$, resulting in the corresponding height-thickness ratio from 250 to 600. As illustrated in Fig. 16, effects of height-thickness ratio are similar to the width-height ratio of SPSW - for larger height-thickness ratios, the structural stiffness $K_{\mathrm{e}}$, the shear yielding strength $F_{\mathrm{ym}}$ and shear ultimate strength $F_{\mathrm{um}}$ all became greater, but the average shear stress $\bar{\tau}_{\text {um }}$ becomes smaller.

\section{Development of design rules}

Based on parametric analysis results, for SPSW buckling-restrained by hat-section cold-formed steel members, it is found that the governing parameters of the structural stiffness and shear strengths are the yield strength, width-height ratio and height-thickness ratio of the embedded SPSW. It was assumed that the hat-section cold-formed steel members, that satisfies the requirements of Eqs. (4)-(12), can fully exert the buckling constraint effect on the embedded SPSW. In this study, 104 models of SPSW buckling-restrained by hat-section cold-formed steel members satisfying Eqs. (4)-(12) were established. Within the range of steel strength grade from Q235 to Q420, width-height ratio from 0.6 to 2.5 , and height-thickness ratio from 250 to 600 , based on the theoretical with numerical analysis, a design method of the buckling-restrained SPSW structure is proposed in this section. The two-stage skeleton curve of the lateral force resistance of the reaction structure shown in Fig. 8 which can be determined by calculating the stiffness $K_{\mathrm{e}}$, the shear yielding strength $F_{\text {ym }}$ and the shear ultimate strength $F_{\text {um }}$ of the buckling-restrained SPSW structure. 


\subsection{Stiffness}

303 As shown in Fig. 8, at the elastic stage, the hat-section members and the SPSW slide in the plane, 304 and the lateral stiffness of the structure is provided by the shear deformation of the SPSW. According 305 to the Hooke's law [23], the relationship between the shear stress $\tau$ and the shear strain $\gamma$ of steel 306 plate are described by Eq. (14):

$$
\tau=G \cdot \gamma
$$

where, $G$ is the shear modulus of steel $\left(7.9 \times 10^{4} \mathrm{~N} / \mathrm{mm}^{2}\right)$.

$$
\begin{array}{lc}
\text { Before yielding } & \tau=\frac{F}{L \cdot t}=G \cdot \gamma=G \cdot \theta \\
\text { Structural stiffness } & K_{\mathrm{e}}=\frac{F}{\theta}=G \cdot L \cdot t
\end{array}
$$

\section{$308 \quad 5.2$ Shear yielding strength}

309 For buckling restrained SPSW, the yield strength might be enhanced by the external members (i.e. 310 the hat-section cold-formed steel members in this study). However, considering the effect of cyclic 311 hardening of buckling-restrained SPSW structure in practice is not as good as that observed in test, 312 therefore, it is suggested to ignore this enhancement in practical design for safety reasons. That is to 313 say, the shear yielding strength of the SPSW buckling-restrained by hat-section cold-formed steel 314 members structure $\left(F_{\mathrm{ym}}\right)$ is calculated by Eq. (17). It should be noted that this conclusion is restricted 315 to buckling-restrained SPSW structures which satisfied the requirements of Eqs. (4)-(12).

$$
F_{\mathrm{ym}}=F_{\mathrm{y}}=\frac{f_{\mathrm{y}}}{\sqrt{3}} \cdot l_{\mathrm{w}} \cdot t_{\mathrm{w}}
$$

\section{$316 \quad 5.3$ Shear ultimate strength}

317 Similarly, a ratio $\left(\xi_{\mathrm{m}}\right)$ of the structural shear ultimate strength $F_{\text {um }}$ to the nominal shear yielding 318 strength $F_{\mathrm{y}}$ is introduced (see Eq. (18)) to reflect the improvement of the shear ultimate strength of 319 the structure owning to the contribution of hat-section steel members.

$$
\xi_{\mathrm{m}}=\frac{F_{\mathrm{um}}}{F_{\mathrm{y}}}
$$

Considering the effects of the governing parameters such as the yield strength $f_{\mathrm{y}}$, the width-height ratio $\alpha$ and the height-thickness ratio $\lambda$ of SPSW, new design rule for the variable $\xi_{\mathrm{m}}$ is proposed based on the 104 FE parametric analysis results, (see Eq. (19)). Therefore, the shear ultimate strength $F_{\text {um }}$ of the SPSW buckling-restrained by hat-section steel members is suggested to be calculated by Eq. (20): 


$$
\begin{gathered}
\xi_{\mathrm{m}}=0.101\left(3.595-\sqrt{\frac{f_{\mathrm{y}}}{235}}\right)\left(5.026+0.166^{\alpha}\right)\left(0.216+0.97^{\frac{\lambda}{300}}\right) \\
F_{\mathrm{um}}=\xi_{\mathrm{m}} \cdot \frac{f_{\mathrm{y}}}{\sqrt{3}} \cdot L \cdot t
\end{gathered}
$$

\section{$325 \quad 5.4$ An equivalent cross-bar model}

326 In the global analysis of high-rise buildings, a cross-bar model is normally used to simplify the 327 SPSW structure. In this study, a cross-bar model (see Fig. 17) of the SPSW buckling-restrained by 328 hat-section cold-formed steel members is proposed to provide equivalent structural stiffness and strength, which could be used in the computational analysis programmes such as SAP2000 and ETABS, etc. The member $\mathrm{AB}$ is identical to the member $\mathrm{CD}$, oblique to each other and hinged to the upper and lower frames at both ends.

Fig. 18 shows the deformation of cross-bar model under a lateral force $F$, i.e. the two bar ends $\mathrm{C}$ and $\mathrm{B}$ generate the same horizontal lateral displacement $\Delta$, and two bars shift to $\mathrm{AB}$ ' and $\mathrm{C}^{\prime} \mathrm{D}$ respectively after deformation. When the cross-bar produces a horizontal side shift $\Delta$, a certain axial deformation $\delta$ and a reaction force of the bars $\mathrm{AB}$ and $\mathrm{CD}$ are generated. According to the small deformation geometric relationship and the material mechanics, the relationship between force $F$ and horizontal deformation $\Delta$ is described by Eqs. (21)-(27).

Assuming that the horizontal displacement is much less than the length of the bar, then,

$$
\delta=\Delta \cdot \cos \theta=\Delta \cdot \frac{L}{\sqrt{L^{2}+H^{2}}}
$$

Then, the strain $\varepsilon$ of the cross-bar is:

$$
\varepsilon=\frac{\delta}{\sqrt{L^{2}+H^{2}}}=\cdot \frac{L}{L^{2}+H^{2}} \cdot \Delta
$$

The axial force of the bar $\mathrm{AB}^{\prime}$ is:

$$
F_{\mathrm{AB}^{\prime}}=E_{\mathrm{s}} \varepsilon A=\frac{L}{L^{2}+H^{2}} \cdot E_{\mathrm{s}} A \cdot \Delta
$$

Hence,

$$
F_{\mathrm{AB}^{\prime}} \cdot \cos \theta=\frac{L^{2}}{\left(L^{2}+H^{2}\right)^{\frac{3}{2}}} \cdot E_{\mathrm{s}} A \cdot \Delta
$$

Similarly,

$$
\begin{aligned}
& F_{\mathrm{DC}}=E_{\mathrm{s}} \varepsilon A=\frac{L}{L^{2}+H^{2}} \cdot E_{\mathrm{s}} A \cdot \Delta \\
& F_{D C^{\prime}} \cdot \cos \theta=\frac{L^{2}}{\left(L^{2}+H^{2}\right)^{\frac{3}{2}}} \cdot E_{s} A \cdot \Delta
\end{aligned}
$$

To sum up, 


$$
F=F_{\mathrm{AB}^{\prime}} \cdot \cos \theta+F_{\mathrm{DC}^{\prime}} \cdot \cos \theta=\frac{2 L^{2}}{\left(L^{2}+H^{2}\right)^{\frac{3}{2}}} E_{\mathrm{s}} A_{\mathrm{s}} \cdot \Delta
$$

where, $A_{\mathrm{s}}$ and $E_{\mathrm{s}}$ are the section area and elastic modulus of the bars, respectively.

Eqs. (21)-(27) defines the elastic characteristic of the cross-bar model. In order to define a cross-bar model for determining the characteristics of buckling-restrained SPSW structure after yielding, the following key parameters should be provided: the structural stiffness $K_{\mathrm{e}}$ (see Eq. (16)), the yield shear strength $F_{\text {ym }}$ (see Eq. (17), the ultimate shear strength $F_{\text {um }}$ (see Eq. (20)) and the ultimate displacement angle $\theta_{\mathrm{u}}=0.02$ of buckling-restrained SPSW structure; the width $L$, the height $H$, the material elastic modulus $E_{\mathrm{s}}$, the reinforced modulus $E_{\mathrm{s} 1}$, the yield stress $f_{\mathrm{ys}}$, the ultimate strength $f_{\text {us, }}$ and the cross-sectional area $A_{\mathrm{s}}$ of the bars.

According to the Fig. 8, Eqs. (16) and (27), the structure stiffness $K_{\mathrm{e}}$ is expressed as:

$$
\begin{gathered}
K_{\mathrm{e}}=\frac{F}{\theta}=\frac{F}{\Delta / H} \\
K_{\mathrm{e}}=\frac{F}{\Delta / H}=\frac{2 L^{2} \cdot H}{\left(L^{2}+H^{2}\right)^{\frac{3}{2}}} E_{\mathrm{s}} A_{\mathrm{s}}
\end{gathered}
$$

Thus, the cross-sectional area of the bar can be determined:

$$
A_{\mathrm{s}}=\frac{\left(L^{2}+H^{2}\right)^{\frac{3}{2}}}{2 L^{2} \cdot H \cdot E_{\mathrm{s}}} \cdot K_{\mathrm{e}}
$$

When the buckling-restrained SPSW structure yields, the yield strain $\varepsilon_{\mathrm{y}}$ of the cross-bar is:

$$
\varepsilon_{\mathrm{y}}=\frac{L}{L^{2}+H^{2}} \cdot \Delta_{\mathrm{y}}=\frac{L}{L^{2}+H^{2}} \cdot \theta_{\mathrm{y}} \cdot H=\frac{L \cdot H}{L^{2}+H^{2}} \cdot \frac{F_{\mathrm{ym}}}{K_{\mathrm{e}}}
$$

Afterwards, the material yield strength $f_{\mathrm{ys}}$ of the cross-bar can be determined:

$$
f_{\mathrm{ys}}=E_{\mathrm{s}} \varepsilon_{\mathrm{y}}=\frac{E_{\mathrm{s}} \cdot L \cdot H}{L^{2}+H^{2}} \cdot \frac{F_{\mathrm{ym}}}{K_{\mathrm{e}}}
$$

The two-stage stress-strain relationship was employed for cross-bar material and the reinforced modulus $E_{\mathrm{s} 1}$ of the cross-bar material is:

$$
E_{\mathrm{s} 1}=E_{\mathrm{s}} \cdot \frac{K_{\mathrm{p}}}{K_{\mathrm{e}}}=\frac{E_{\mathrm{s}}}{K_{\mathrm{e}}} \cdot \frac{F_{\mathrm{um}}-F_{\mathrm{ym}}}{\theta_{\mathrm{u}}-F_{\mathrm{ym}} / K_{\mathrm{e}}}
$$

The ultimate strength $f_{\text {us }}$ of the cross-bar material is:

$$
f_{\text {us }}=\frac{F_{\text {um }}}{F_{\text {ym }}} \cdot f_{\text {ys }}
$$

\section{Result comparisons}

New design equations for the prediction of the stiffness, shear yielding strength and shear ultimate strength of this new type of SPSW structure have been developed in Section 5. Fig. 19 shows the 
363 comparison the structural stiffness $K_{\mathrm{e}}$ between numerical and predicted results. Good agreement is 364 achieved with the mean value of $K_{\mathrm{e} 1} / K_{\mathrm{e} 2}$ is found to be 1.02 .

365 As shown in Fig. 20, for the specimens NRSP1, NRSP2, NRSP3 and NRSP6 which are 366 satisfying Eqs. (4)-(12), the predicted results of $F_{\text {um }}$ are in good agreement with numerical (and 367 experimental) results of $F_{\text {um }}$ with good accuracy and consistency - the mean value of the predicted 368 results to numerical (and experimental) results is 1.001 and the corresponding coefficient of variation $369(\mathrm{COV})=0.0069$, variance $=0.009$.

\section{$370 \quad 7$ Conclusions}

A finite element model of the steel plate shear wall (SPSW) buckling-restrained by hat-section cold-formed steel members was developed and validated against the existing experimental results in terms of failure modes, shear force-story drift angle curves and shear strength. In the parametric study, a total of 104 numerical results were generated to consider six key parameters of this new buckling-restrained SPSW structure, including spacing of connecting bolts, geometries of hat-section steel, spacing of hat-section steel, steel material strength, width-height ratio of the SPSW and height-thickness ratio of the SPSW. Numerical results show that: (1) effects of all the aforementioned parameters on the structural stiffness of the buckling-restrained SPSW structure are limited; (2) with the increase of the width-height, the shear yielding strength and shear ultimate strength of SPSW increase linearly; (3) the shear yielding strength and shear ultimate strength increase as the height-thickness ratio decreases; (4) with the decrease of the spacing of hat-section cold-formed steel members, the shear yielding strength improves slightly, but its effect on the shear ultimate strength is negligible when it is less than $450 \mathrm{~mm}$. Based on numerical study and theoretical analysis, requirements on the geometries of this new buckling-restrained SPSW structure are suggested to ensure effective buckling-restraint on the SPSW. Within the range of steel strength grade from Q235 to Q420, width-height ratio from 0.6 to 2.5, and height-thickness ratio from 250 to 600 , new design equations for the prediction of structural stiffness, shear yielding strength and shear ultimate strength of this new buckling-restrained SPSW structure are proposed. In addition, a cross-bar model as a simplified equivalent model for the SPSW buckling-restrained by hat-section cold-formed steel members is proposed, which could be used in the computational analysis programmes such as SAP2000 and ETABS, etc. By comparing the predicted results with experimental and numerical results, the proposed design method is found to be accurate and consistent. 


\section{Acknowledgments}

397 The research is supported by Scientific Research Fund of Institute of Engineering Mechanics, China

398 Earthquake Administration (Grant No. 2018D13), National Key Research and Development Program 399 of China (2017YFC0703406), the "111" Project (B18062), the Fundamental Research Fund for the 400 Central Universities (2019CDQYTM028), Project of Chongqing science and technology Bureau 401 (cstc2019jcyj-zdxm0088) and Open Project of Key Laboratory of New Technology for Construction 402 of Cities in Mountain Area (LNTCCMA-20200106).

403

404 Nomenclature

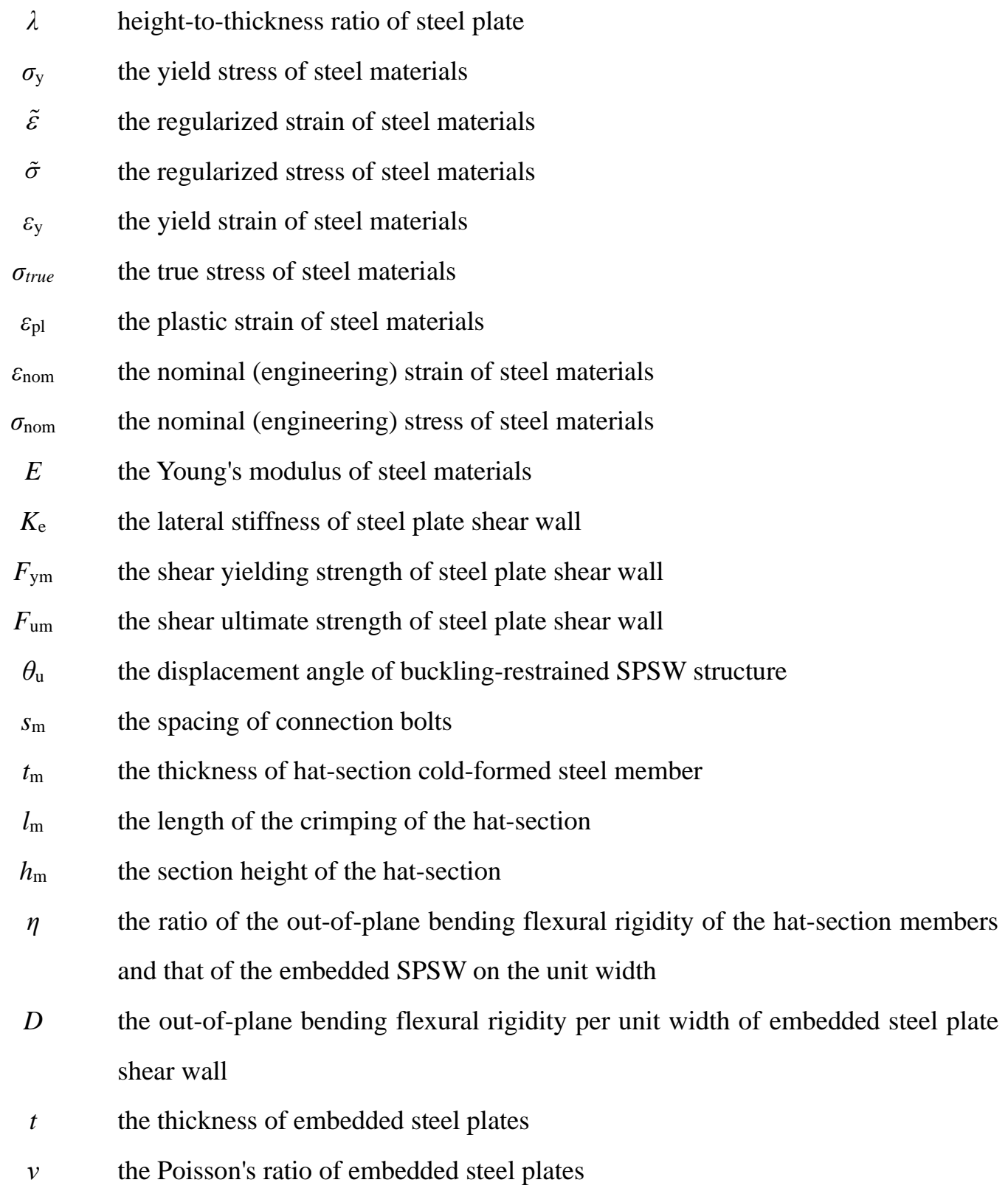




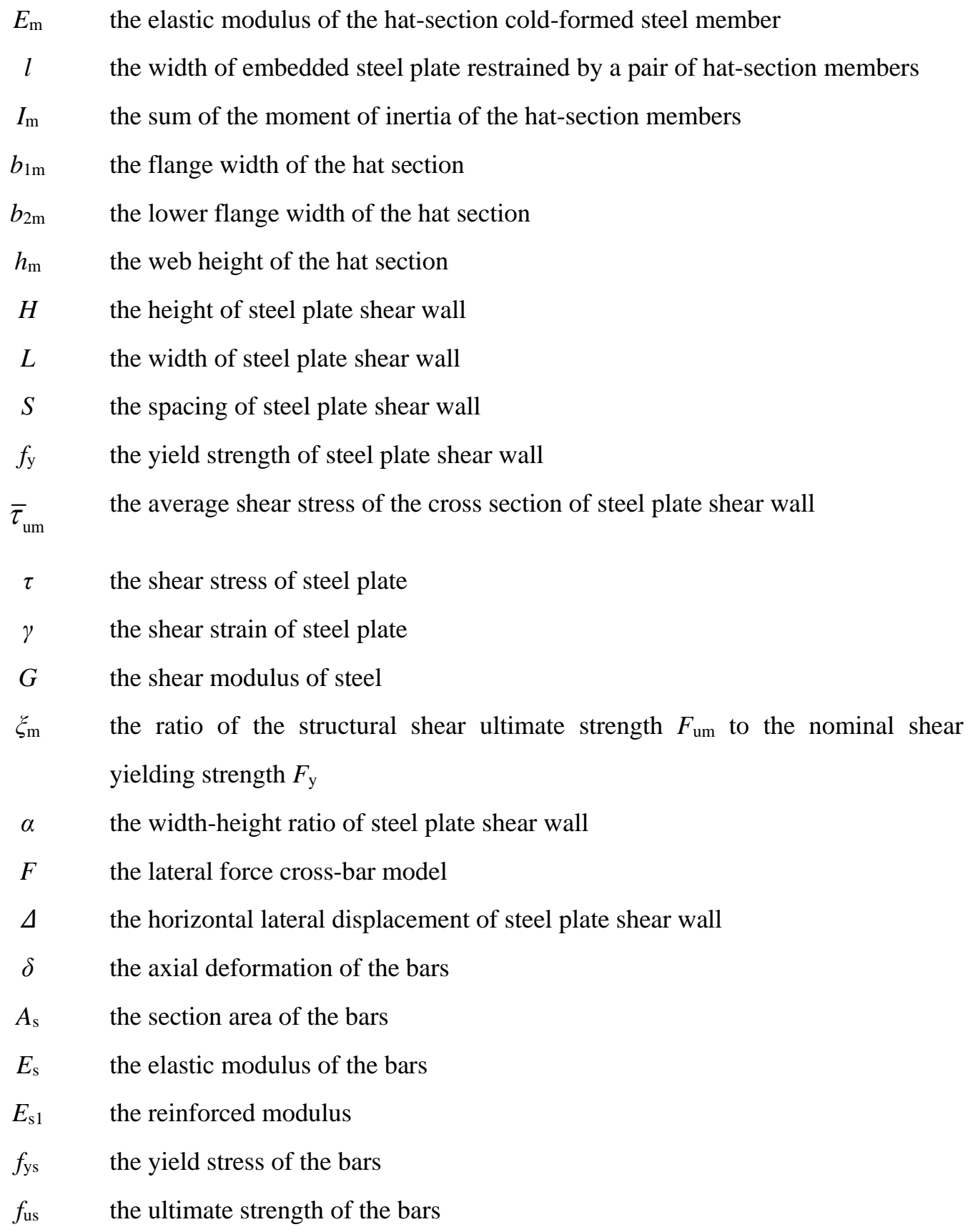

407 [1] Dowden DM, Bruneau M. Quasi-static cyclic testing and analytical investigation of steel plate 408 shear walls with different post-tensioned beam-to-column rocking connections. Engineering $409 \quad$ Structures, 2019, 187:43-56.

410 [2] Liu WY, Li GQ, Jiang J. Mechanical behavior of buckling restrained steel plate shear walls with 411 two-side connections. Engineering Structures, 2017, 138:283-292. 
[3] Bypour M, Gholhaki M, Kioumarsi M , et al. Nonlinear analysis to investigate effect of connection type on behavior of steel plate shear wall in RC frame. Engineering Structures, 2019, 179:611-624.

[4] Ozcelik Y, clayton PM. Seismic design and performance of SPSWs with beam-connected web plates. Journal of Constructional Steel Research, 2018, 142: 55-67.

[5] Guo YL, Zhu JS QL, Zhou P, Zhu BL. A new shuttle-shaped buckling-restrained brace. Theoretical study on buckling behavior and load resistance. Engineering Structures, 2017, 147:233-241.

[6] Driver RG, Kulak GL, Kennedy DJL, et al. Cyclic Test of Four-story Steel Plate Shear Wall. Journal of Structural Engineering, ASCE, 1998, 124(2): 112-120.

[7] Lubell AS, Helmut GL, el al. Unstiffened Steel Plate Shear Wall Performance Under Cyclic Loading. Journal of Structural Engineering, 2000,126(4):453-460.

[8] Takanashi Y, Takemoto T, Tagaki M. Experimental Study on Thin Steel Shear Walls and Particular Bracing Under Alternative Horizontal Load//Resistance and Ultimate Deformability of Structures Acted on by Well-Defined Repeated Loads. Portugal:1973.

[9] Ge ML, Hao JP, Yu JG, Yan PZ, Xu SC. Shaking table test of buckling-restrained steel plate shear walls. Journal of Constructional Steel Research, 2017, 137:254-261.

[10] Thorburn LJ, Kulak GL, Montgomery CJ. Analysis of steel plate shear walls. Department of civil engineering, the university of Alberta, Edmonton, Alberta, 1983.

[11] Yu JG, Yu HS, Feng XT, Dang C, Hou TF, Shen J. Behaviour of steel plate shear walls with different types of partially-encased H-section columns. Journal of Constructional Steel Research, 2020, 170:106123.

[12] Moghimi H , Driver R G . Performance-Based Capacity Design of Steel Plate Shear Walls. I: Development Principles. Journal of Structural Engineering, 2014, 140(12):04014097.

[13] Moghimi H , Driver R G . Performance-Based Capacity Design of Steel Plate Shear Walls. II: Design Provisions. Journal of Structural Engineering, 2014, 140(12):04014098.

[14] Wang YH, Gu CW, Tang Q, Shi Y, Xu L, Tan JK, Luo W. Experimental Study on Cyclic Pure Shear Behaviour of Hat-Section Cold-formed steel members Buckling-Restrained Steel Plate Shear Walls without Effect of Frame. Engineering Structures, 2019, 201:109799.

[15] JGJ 101-2015 Specification of testing methods for earthquake resistant building. Beijing: China Architecture \& Building Press,2015

[16] ABAQUS, ABAQUS/Standard Version 6.14 User's Manual vols. I-III, Dassault Systèmes Simulia Corp, Rhode Island, USA, 2014.

[17] Shi YJ, Wang M, Wang YQ. Study on constitutive model of structural steel under cyclic loading. Engineering Mechanics,2012,29(09):92-98+105. 
447 [18] Chen MT, Young B. Behavior of cold-formed steel elliptical hollow sections subjected to 448 bending. Journal of Constructional Steel Research, 2019, 158: 317-330.

449 [19] Chen MT, Young B. Structural behavior of cold-formed steel semi-oval hollow section beams.

$450 \quad$ Engineering Structures, 2019, 185: 400-411.

451 [20] Su MN, Young B, Gardner L. Deformation-based design of aluminium alloy beams.

452 Engineering Structures, 2014, 80:339-349.

453 [21] JGJ99-2015 Technical specification for steel structure of tall building. Beijing: China building $454 \quad$ industry press, 2015.

455 [22] Cui J, Long LP. Basic principles of steel structure. China building industry press, 2008.

456 [23] Liu DH, Huang C. material mechanics I. Chongqing university press, 2010.

457 [24] Computers and Structures, Inc. CSI analysis manual, Berkeley, California, USA, 2018.

458 


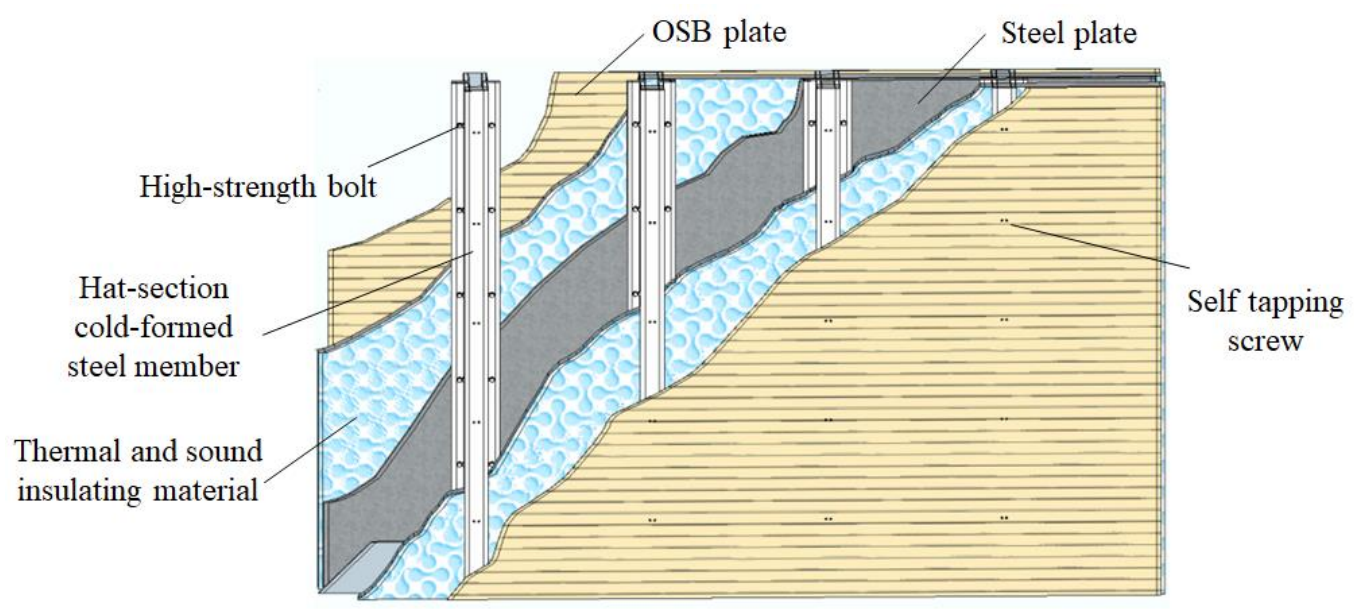

Fig. 1 Steel plate shear wall buckling-restrained by hat-section cold-formed steel 


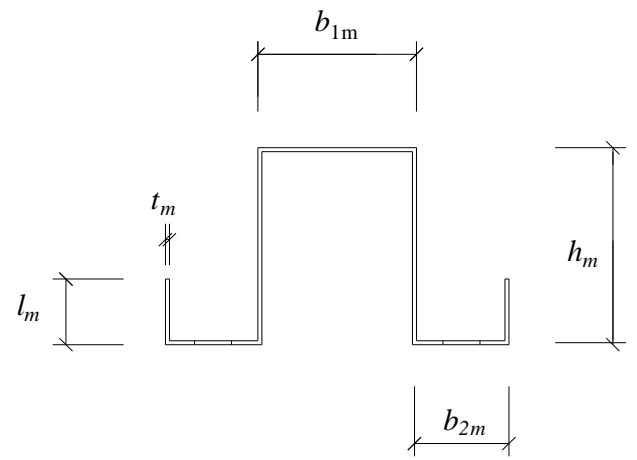

Fig. 2 Dimensions of hat-section cold-formed steel members 


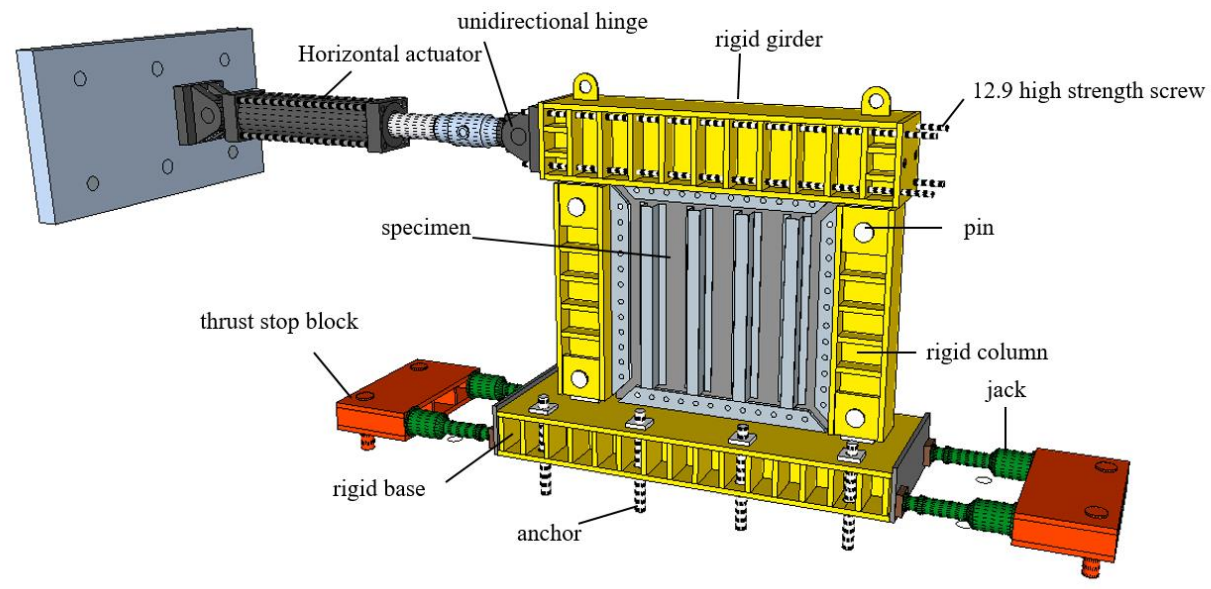

Fig. 3 Schematic drawing of the loading device

466 


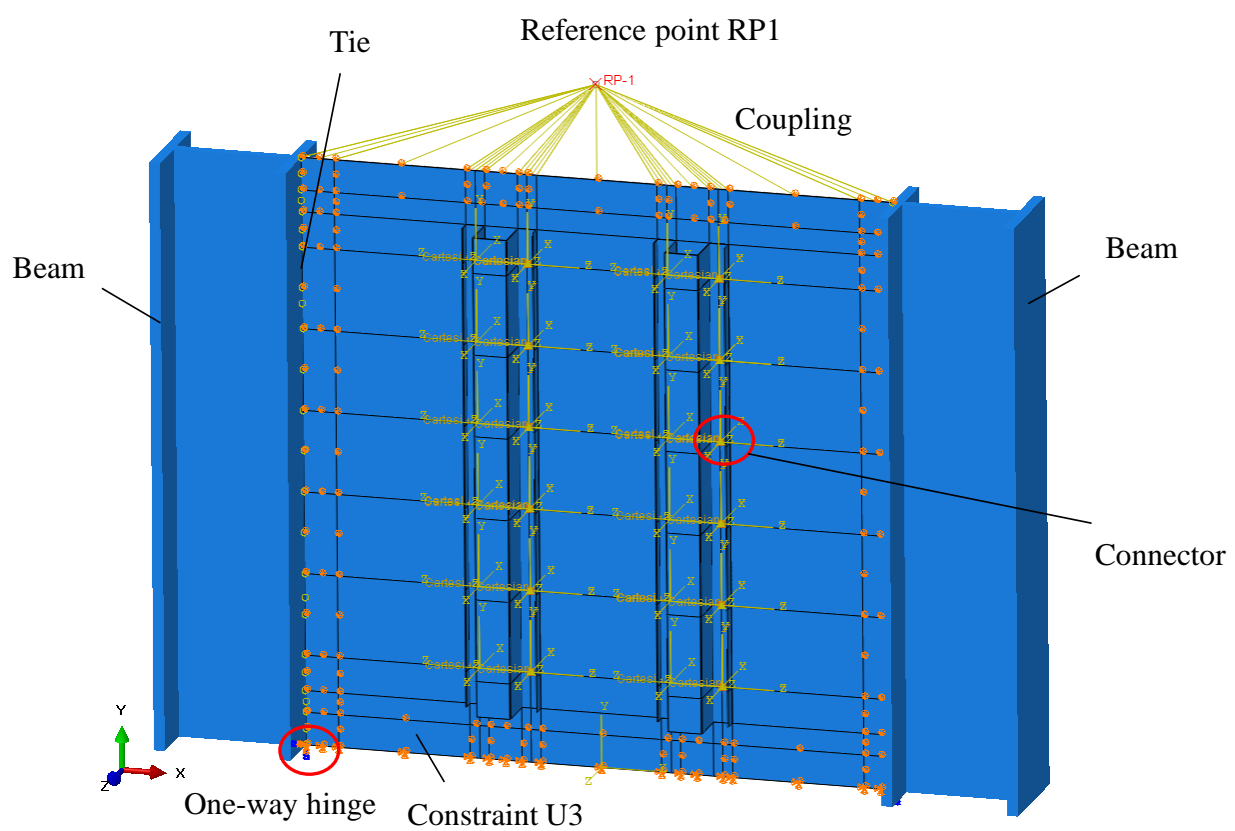

Fig. 4 FE model of SPSW buckling-restrained by hat-section steel members

469 

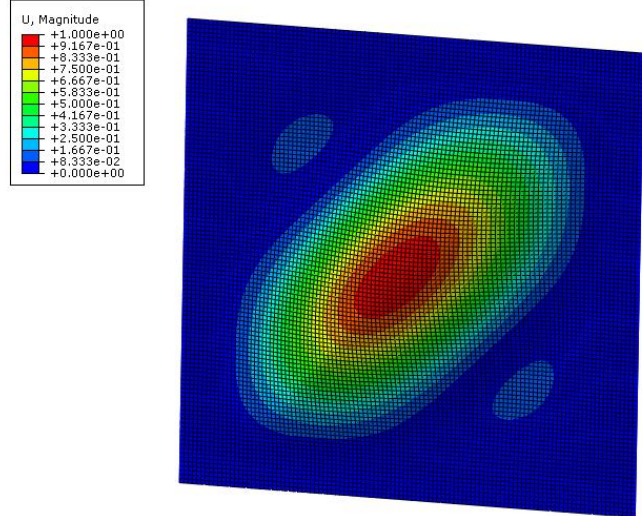

(a) NRSP
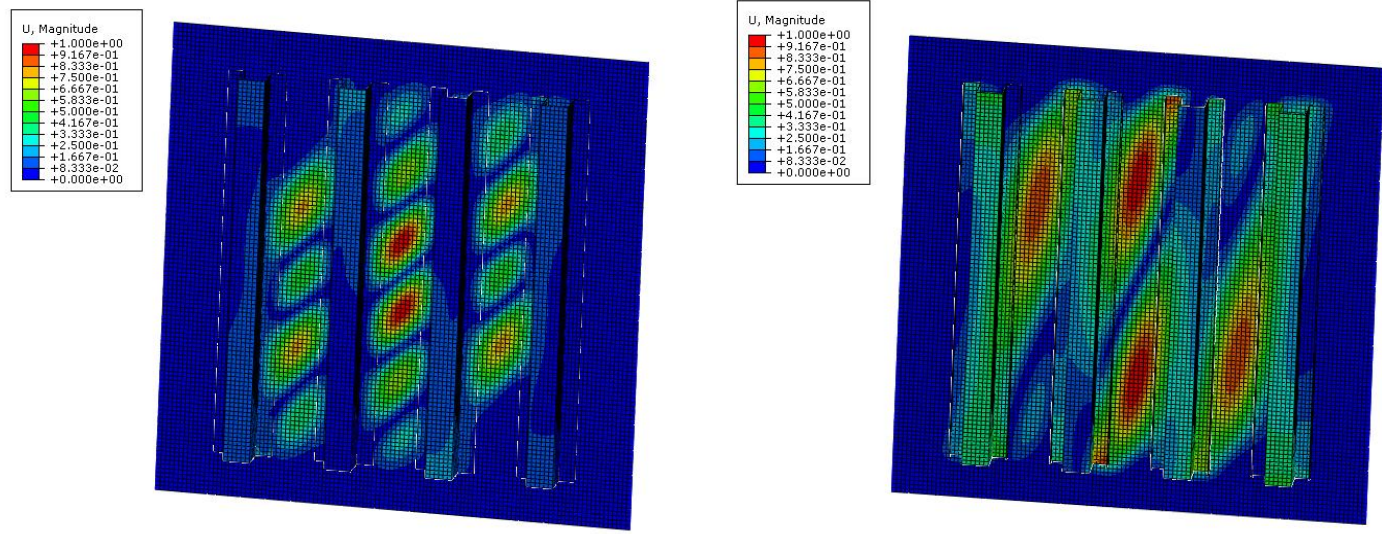

(b) BRSP1

(c) BRSP3

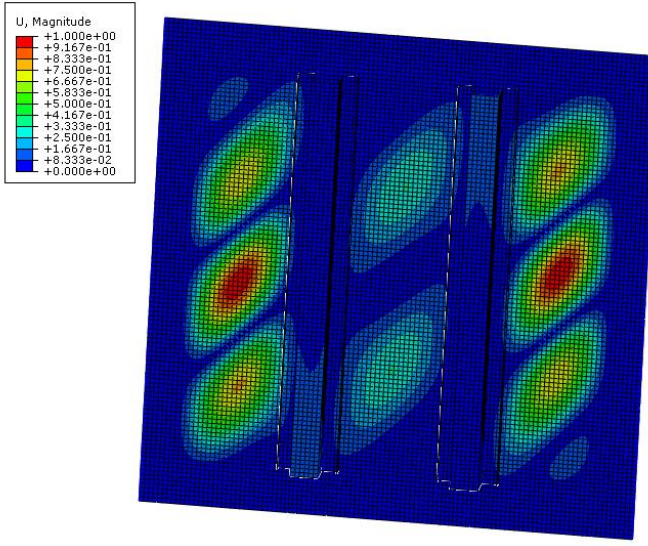

(d) BRSP4

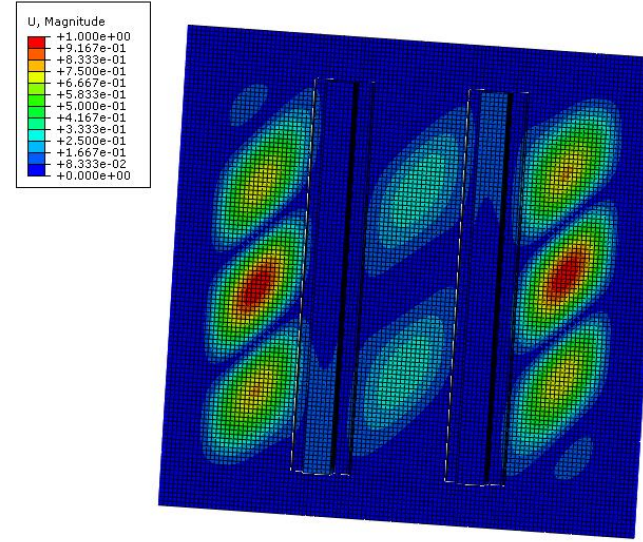

(e) BRSP5

Fig. 5 Buckling modes of specimens obtained from FE models 

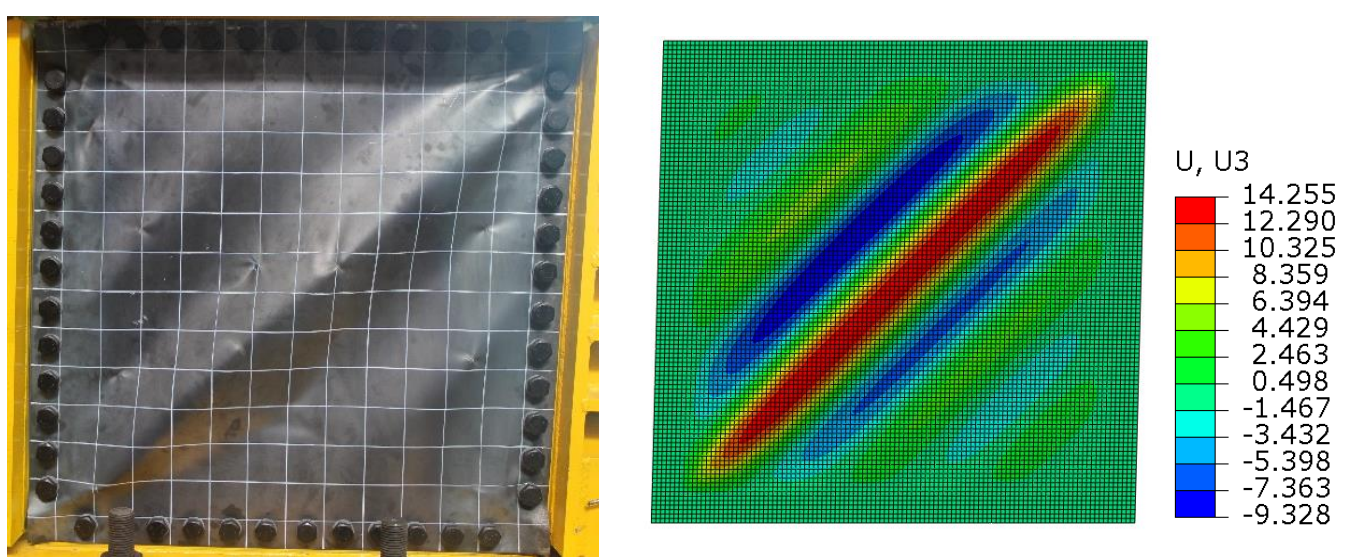

(a) Specimen NRSP
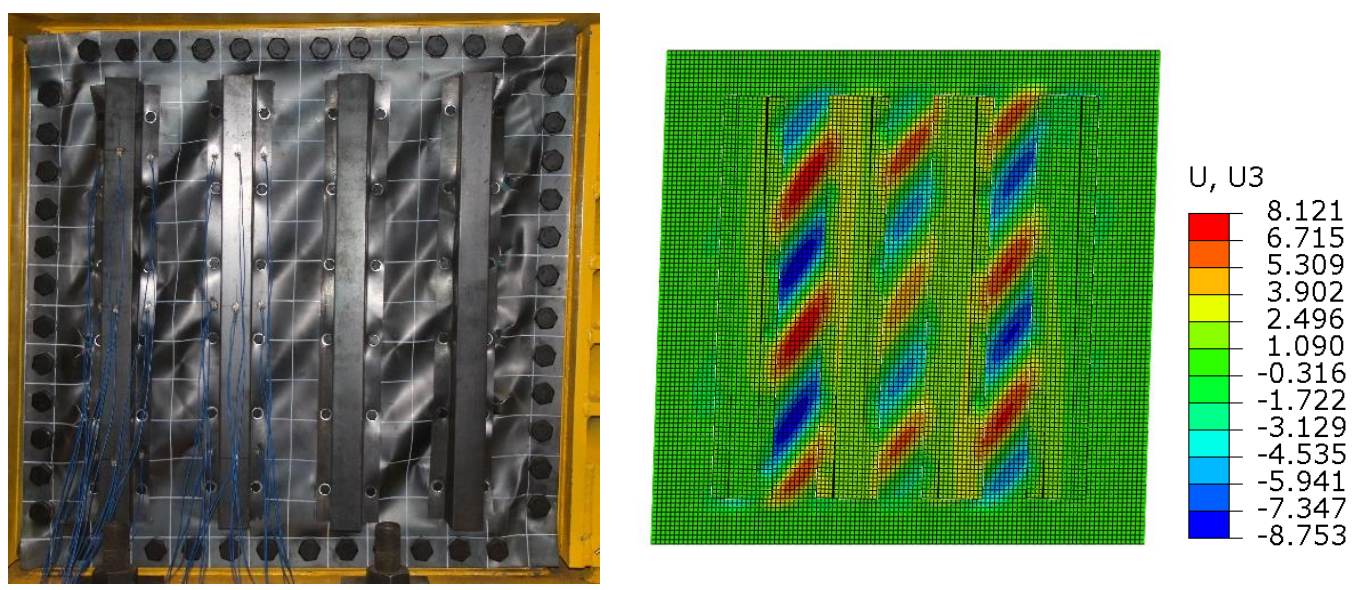

(b) Specimen BRSP1
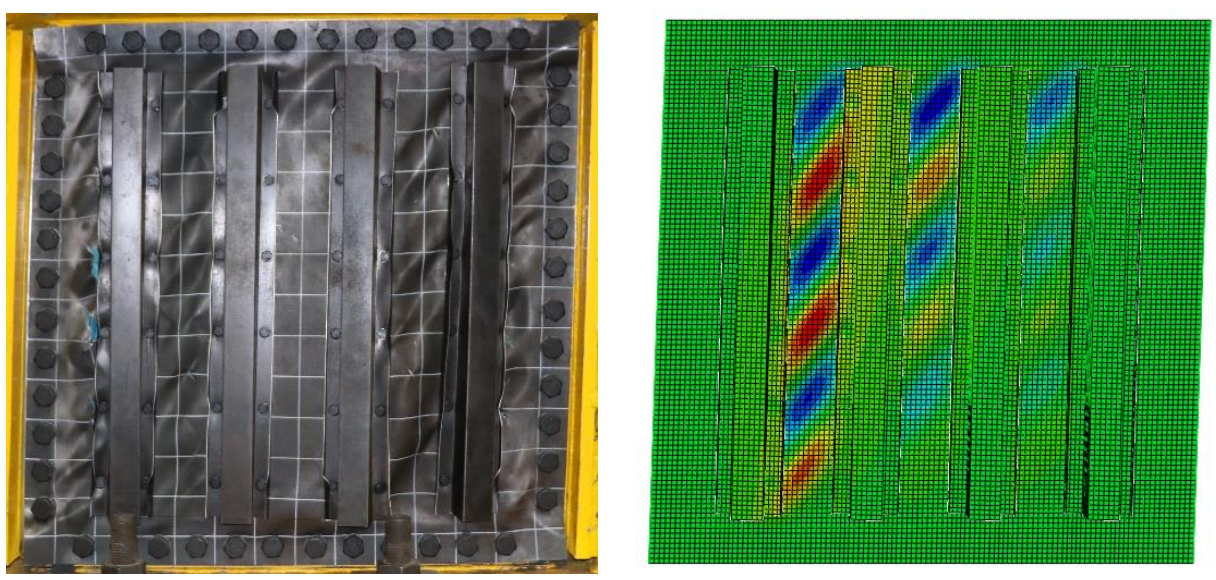

U, U3

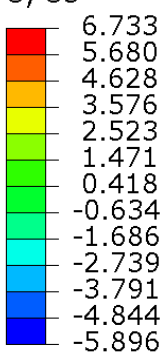

(c) Specimen BRSP3 

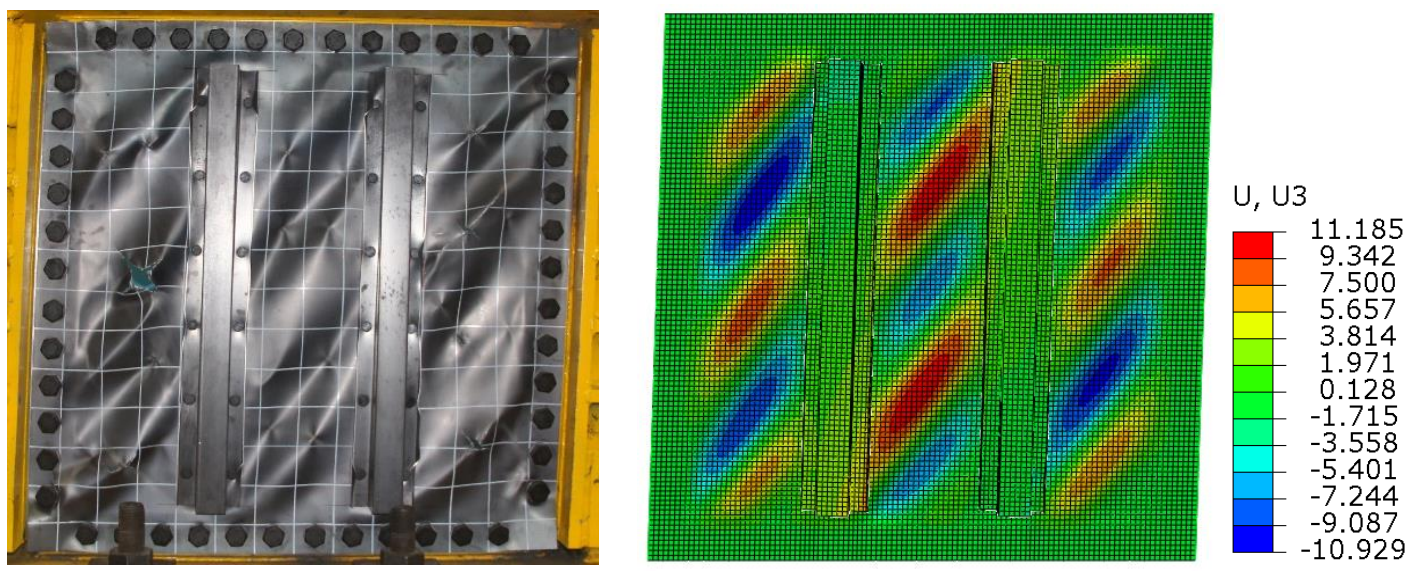

(d) Specimen BRSP4
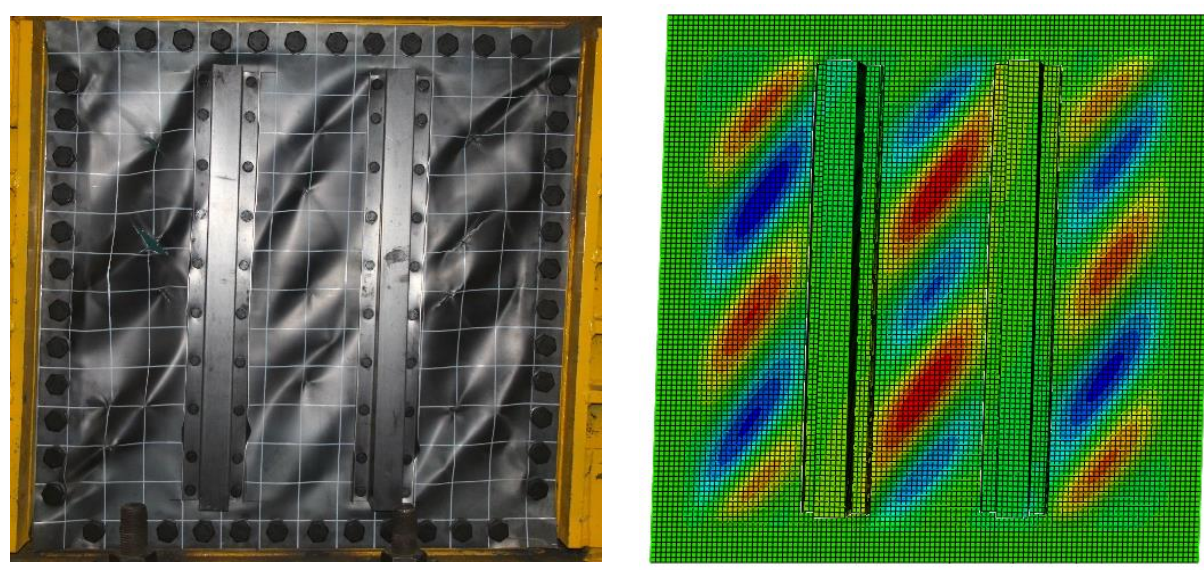

$\mathrm{U}, \mathrm{U3}$

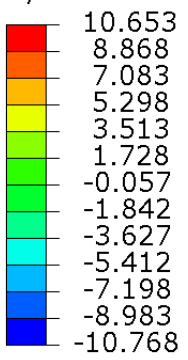

(e) Specimen BRSP5

Fig. 6 Comparison of failure modes between test and FE modelling 


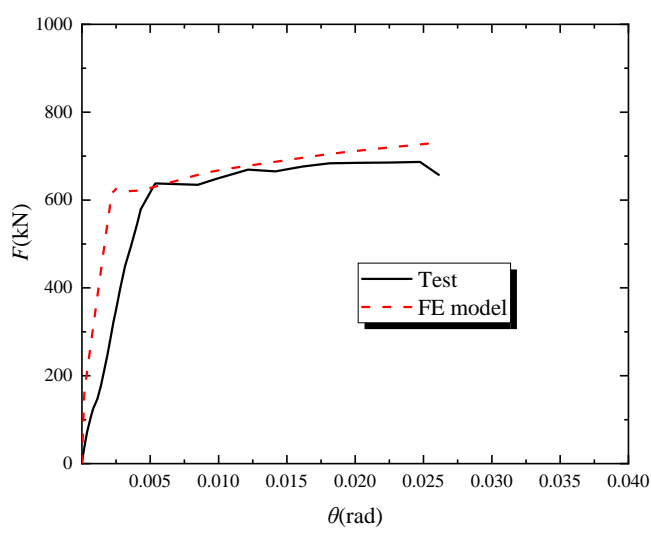

(a) Specimen NRSP

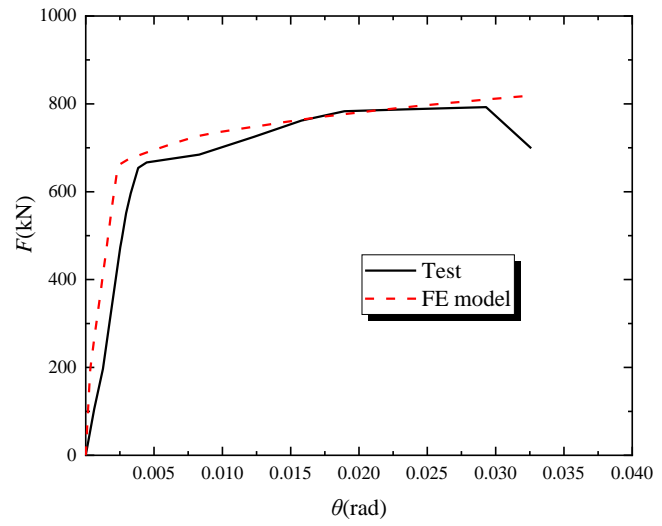

(b) Specimen BRSP1

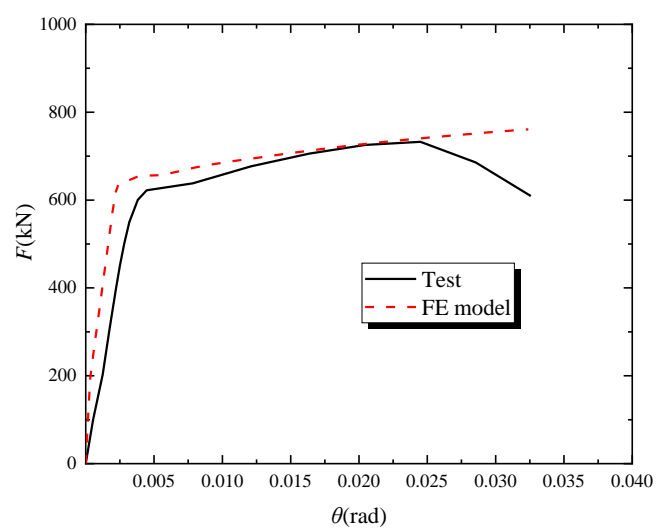

(d) Specimen BRSP4

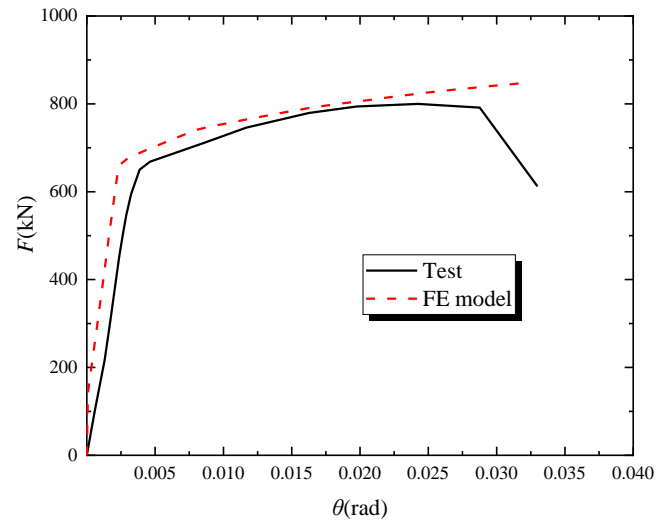

(c) Specimen BRSP3

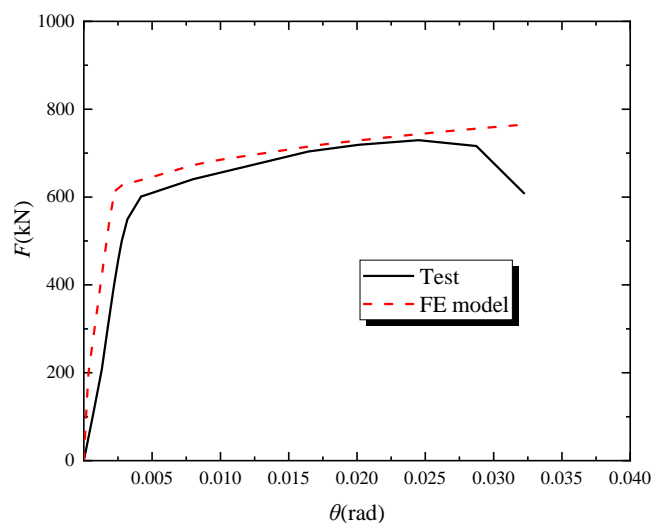

(e) Specimen BRSP5

Fig. 7 Comparison of shear force-story drift angle curves between test and FE modelling 


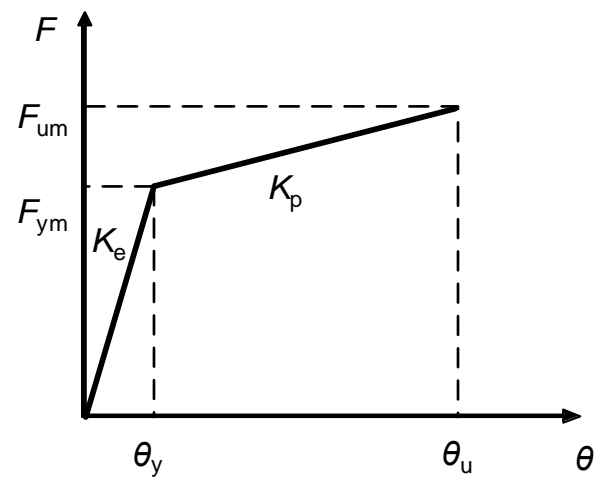

Fig. 8 Two-stage skeleton of $F-\theta$ curve 


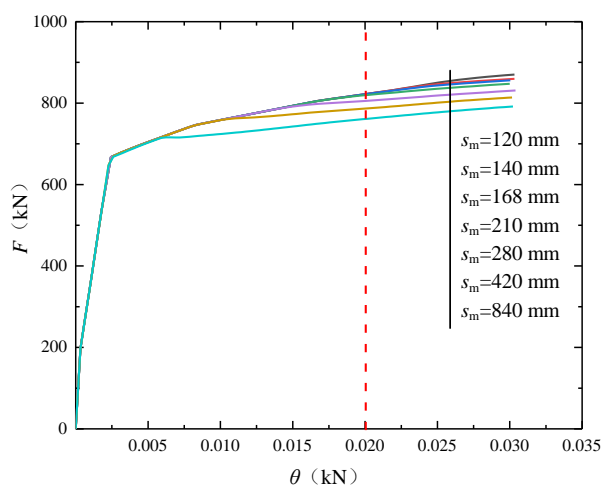

(a) F- $\theta$ curves

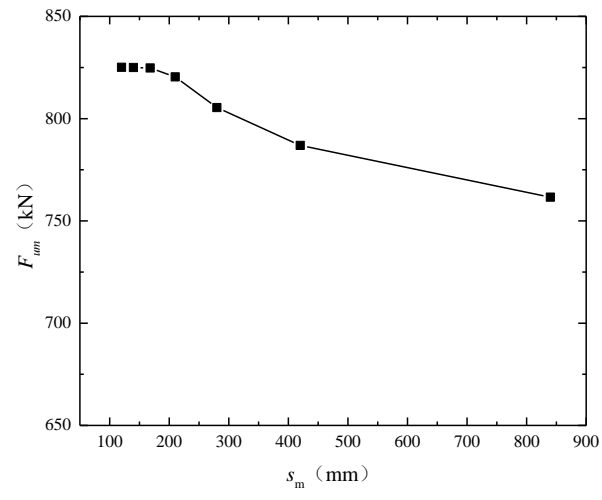

(b) $F_{\text {um}}-S_{\mathrm{m}}$ curve

Fig. 9 Effects of the spacing of connection bolts on the structure performance of SPSW 


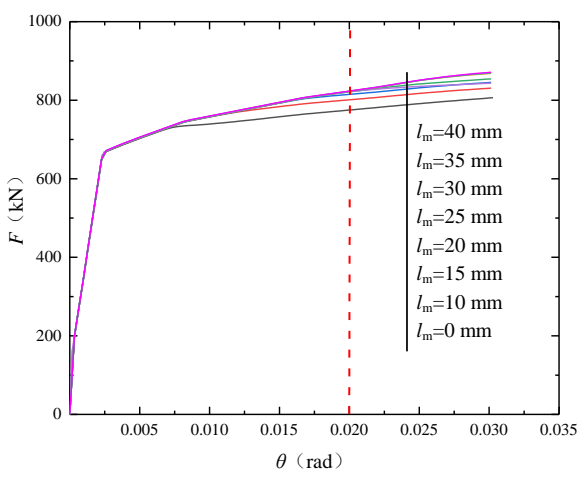

(a) $F-\theta$ curves

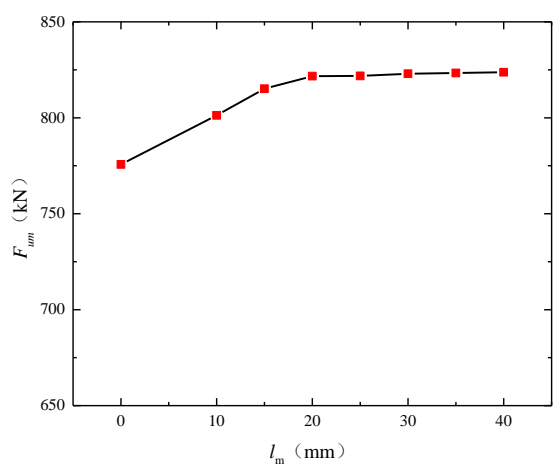

(b) $F_{\text {um- }} l_{\mathrm{m}}$ curve

Fig. 10 Effects of the length of crimping on the structure performance of SPSW 


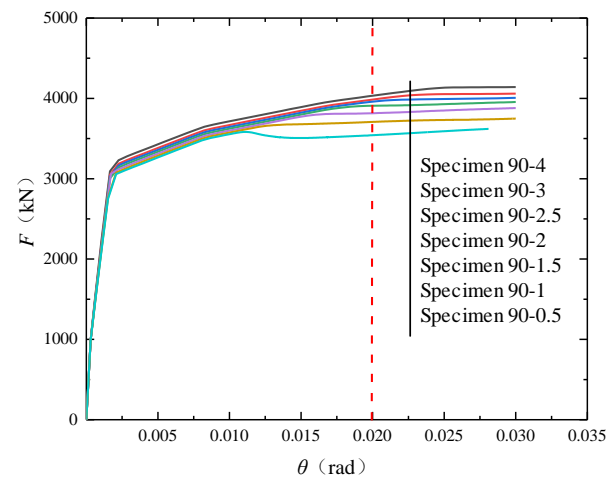

(a) Thickness of the section $t_{\mathrm{m}}$

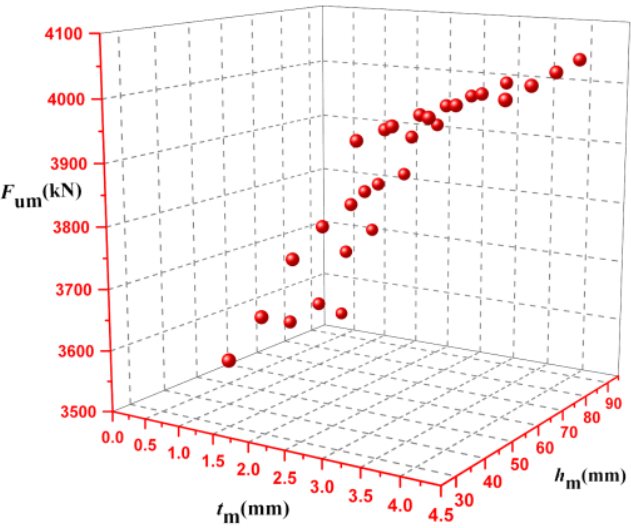

(c) Spatial distribution of shear ultimate strength $F_{\text {um }}$ of the

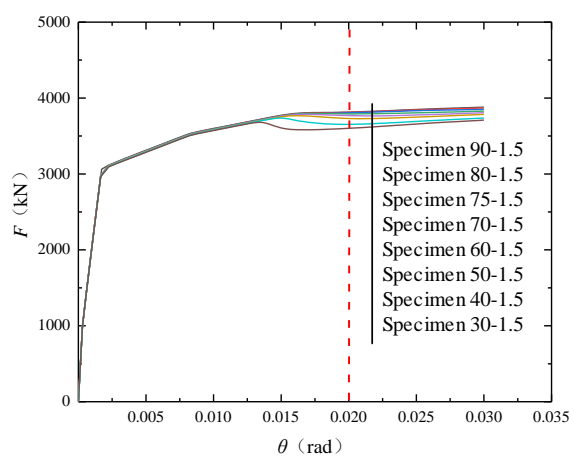

(b) Height of the section $h_{\mathrm{m}}$

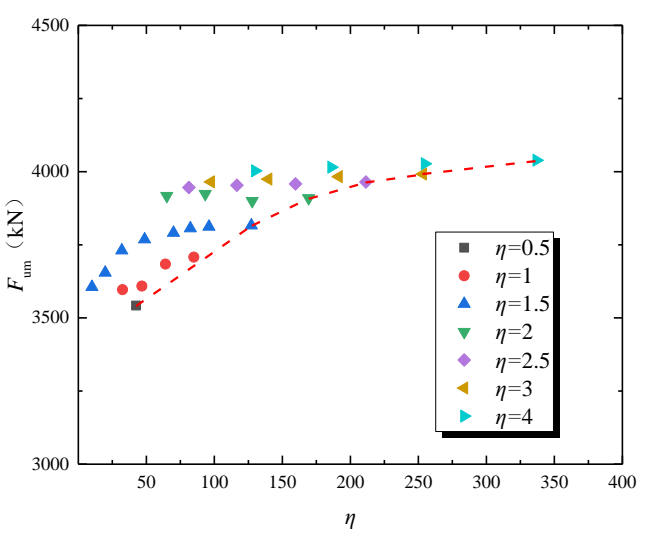

(d) bending stiffness ratio $\eta$

\section{structure}

Fig. 11 Effects of the section design of hat-section steel members on the structure performance of SPSW 


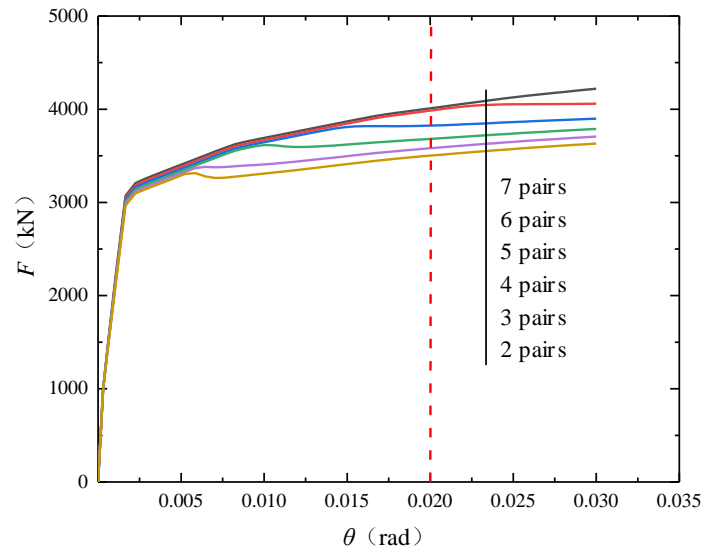

(a) The effects of number of constraints pairs on the $F-\theta$

curves

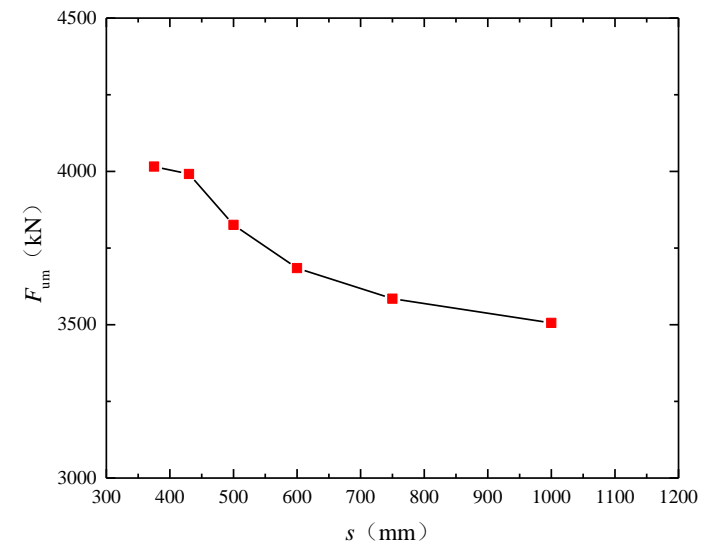

(b) The $F_{\text {um }}-S$ curve

Fig. 12 Effects of the spacing of hat-section steel members on the structure performance of SPSW

492 


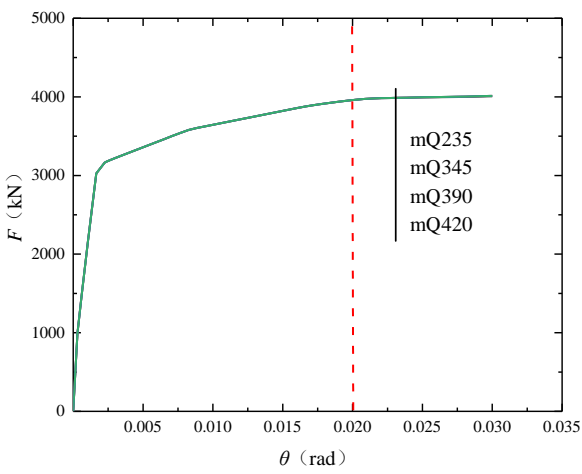

Fig. 13 Effects of yield strength of hat-section cold-formed steel on the $F-\theta$ curves of SPSW 495 


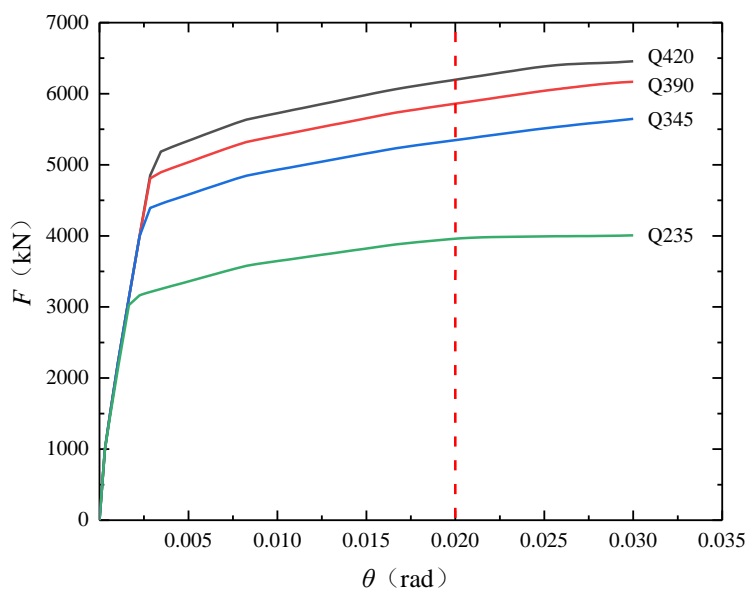

Fig. 14 Effects of yield strength of embedded steel plates on the $F-\theta$ curves of SPSW 498 


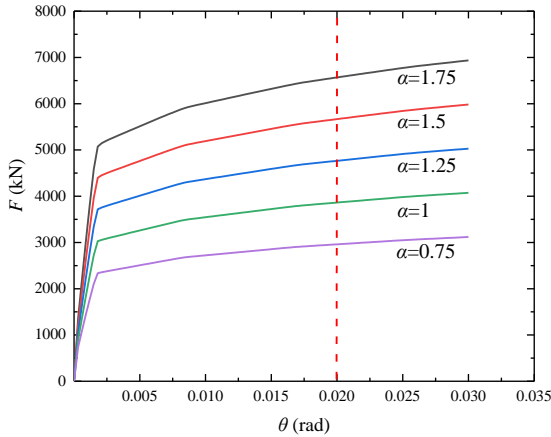

(a) The $F-\theta$ curves

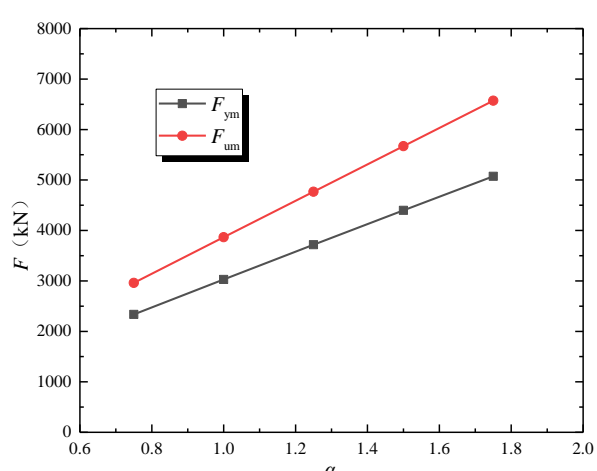

(c) The $F$ - $\alpha$ curves

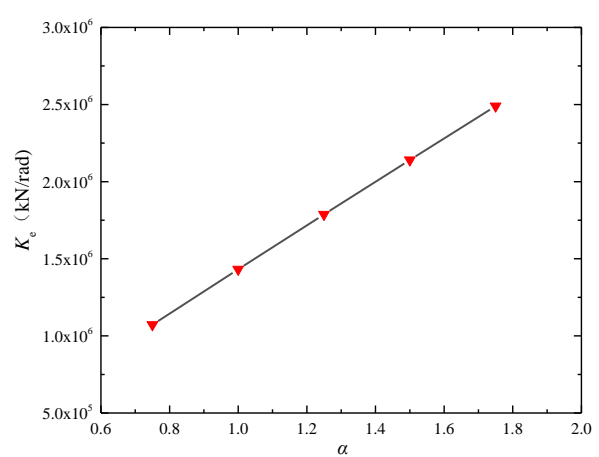

(b) The $K_{\mathrm{e}}-\alpha$ curve

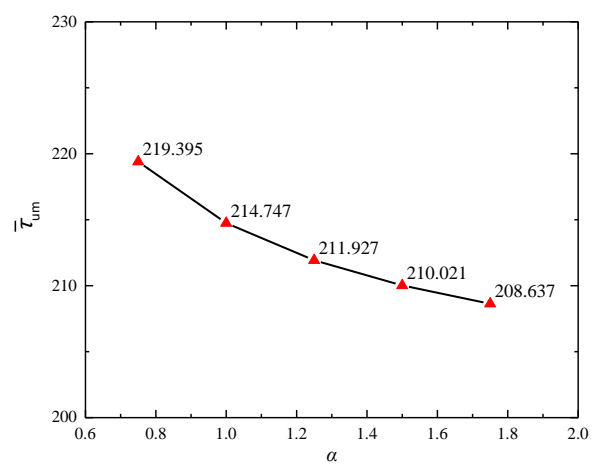

(d) The $\tau_{u m}-\alpha$ curve

Fig. 15 Effects of aspect ratio of embedded steel plates on the structure performance of SPSW

501 


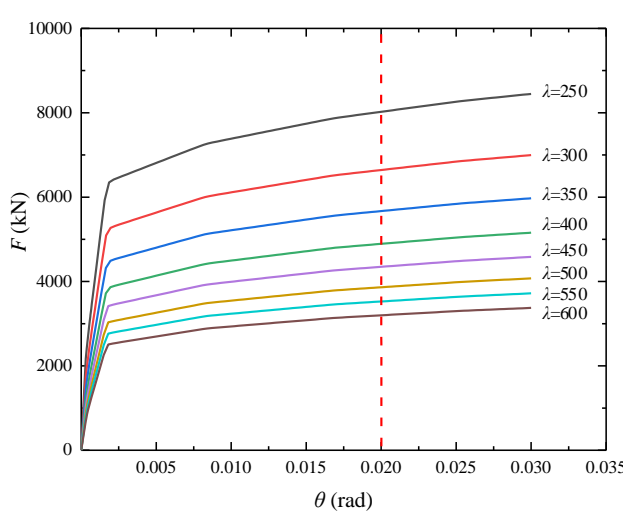

(a) The $F-\theta$ curves

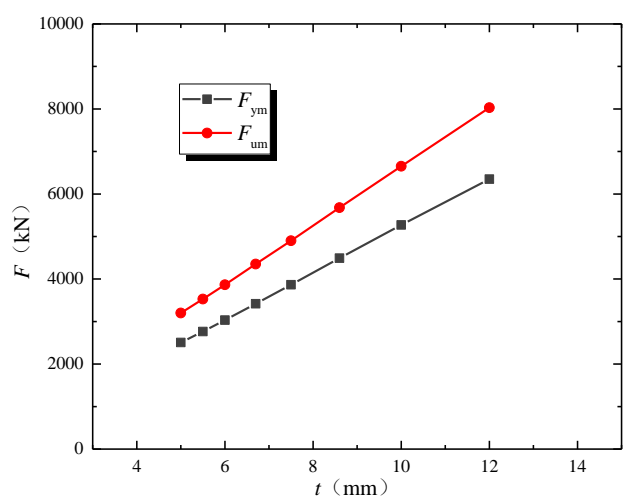

(c) The $F$ - $t$ curves

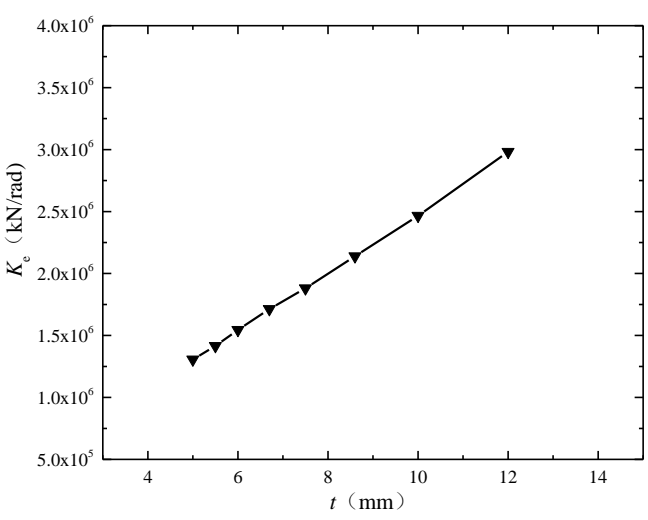

(b) The $K_{\mathrm{e}}-t$ curve

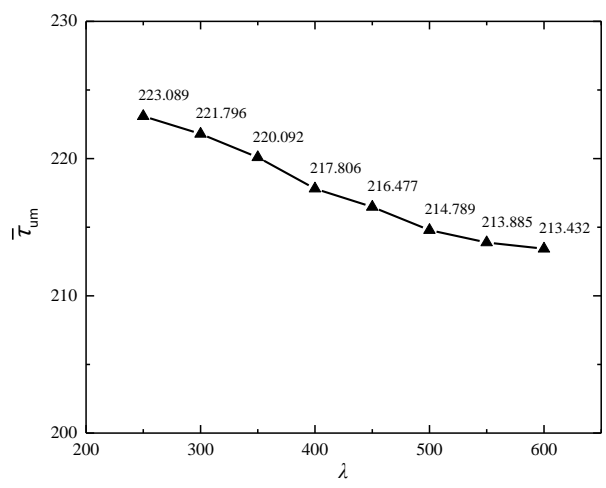

(d) The $\bar{\tau}_{u m-\lambda}$ curve

Fig. 16 Effects of height-thickness ratio of embedded steel plates on the structure performance of SPSW 


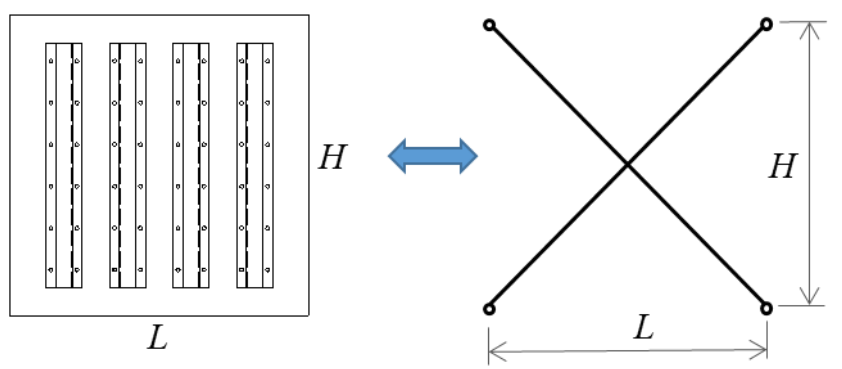

Fig. 17 Equivalent cross-bar model 


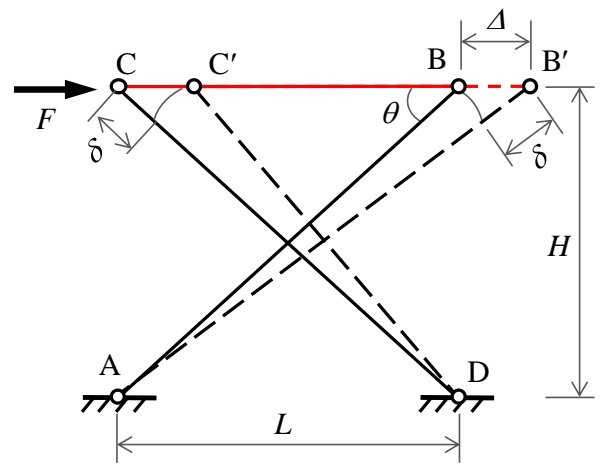

Fig. 18 Deformation of the cross-bar model 


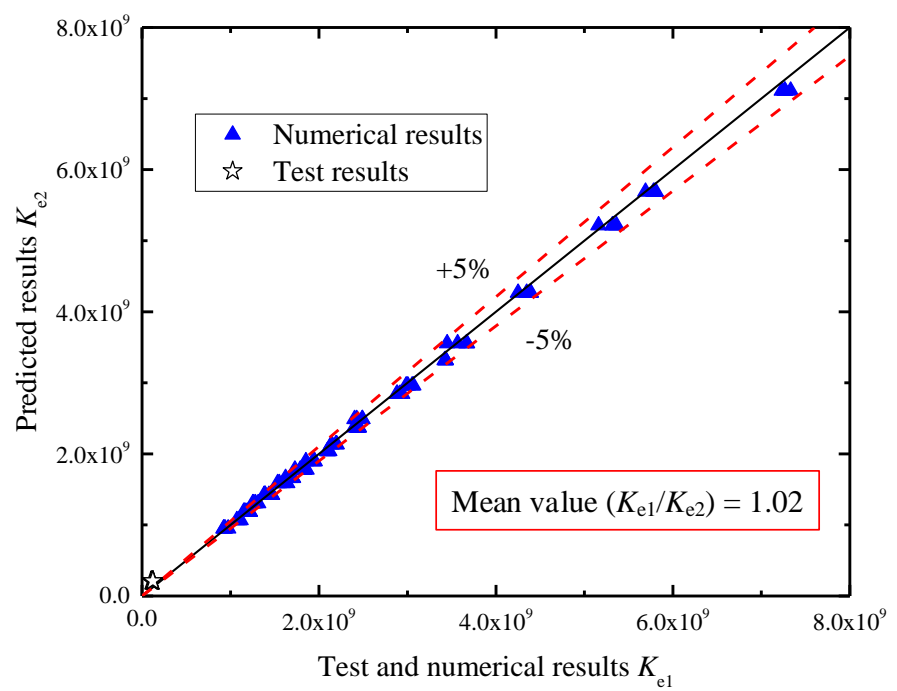

Fig. 19 Comparison of the structural stiffness between predicted results with test and numerical results 512 


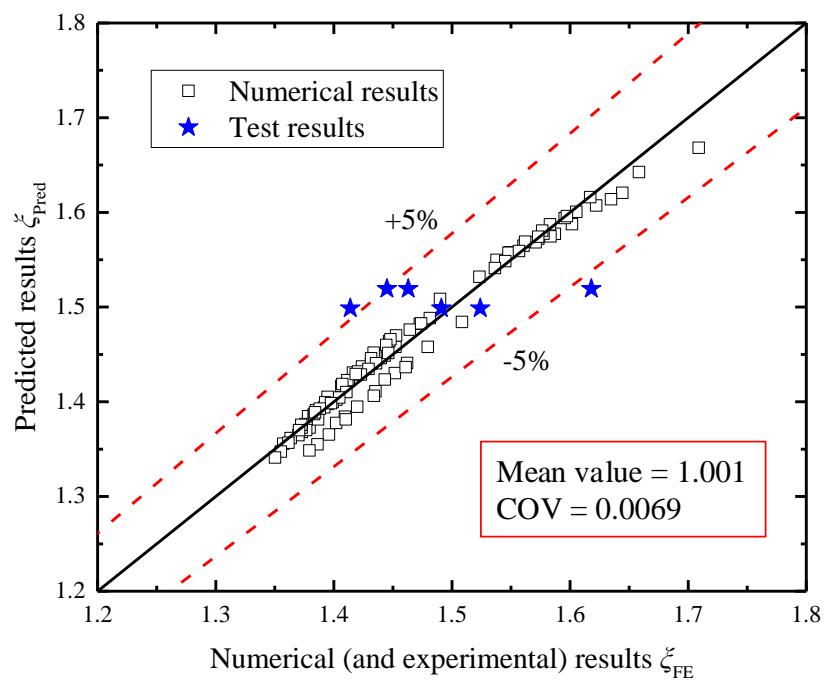

Fig. 20 Comparison between predicted results $\xi_{\text {Pred }}$ with numerical (and experimental) results $\xi_{\mathrm{FE}}$ 


\begin{tabular}{llcc}
\hline Components & Yield strength $f_{\mathrm{y}}$ & Ultimate strength $f_{\mathrm{u}}$ \\
\hline \multirow{3}{*}{ SPSWs } & NRSP & & \\
& BRSP1 & 321.67 & 463.67 \\
& BRSP2 & & \\
& BRSP3 & & 439.33 \\
\cline { 2 - 3 } & BRSP4 & & 551.00 \\
& BRSP5 & 303.67 & 539.67 \\
& BRSP6 & & 550.00 \\
\hline \multirow{3}{*}{ Hat-section cold-formed steel members } & BRSP1 & 427.33 & 541.33 \\
& BRSP2 & 420.00 & 556.00 \\
\hline & BRSP3 & 425.67 & \\
\hline
\end{tabular}

518 
Table 2 Comparison of shear bearing capacities obtained from test [14] and FE modelling

\begin{tabular}{lcccccccc}
\hline & Specimens & NRSP & BRSP1 & BRSP3 & BRSP4 & BRSP5 & Mean & COV \\
\hline \multirow{5}{*}{ Shear yielding strength } & Test $(\mathrm{kN})$ & 637.7 & 654.2 & 650.2 & 622.2 & 601.9 & & \\
& FE $(\mathrm{kN})$ & 629.5 & 666.5 & 669.3 & 632.6 & 613.4 & & \\
& Test/FE & 1.01 & 0.98 & 0.97 & 0.98 & 0.98 & 0.98 & 0.001 \\
\hline \multirow{3}{*}{ Shear ultimate strength } & Test (kN) & 686.7 & 792.4 & 800.0 & 732.5 & 729.3 & & \\
& FE $(\mathrm{kN})$ & 727.3 & 809.4 & 823.2 & 739.8 & 743.8 & & \\
& Test/FE & 0.94 & 0.98 & 0.97 & 0.99 & 0.98 & 0.97 & 0.004 \\
\hline
\end{tabular}

521 